\title{
Vertical profiling of aerosol particles and trace gases over the central Arctic Ocean during summer
}

\author{
P. Kupiszewski ${ }^{1,2}$, C. Leck $^{1}$, M. Tjernström ${ }^{1}$, S. Sjogren ${ }^{3}$, J. Sedlar ${ }^{4}$, M. Graus ${ }^{5,6}$, M. Müller ${ }^{7}$, B. Brooks ${ }^{8}$, \\ E. Swietlicki ${ }^{3}$, S. Norris ${ }^{9}$, and A. Hansel ${ }^{7}$ \\ ${ }^{1}$ Department of Meteorology and Bert Bolin Centre for Climate Research, Stockholm University, 10691 Stockholm, Sweden \\ ${ }^{2}$ Laboratory of Atmospheric Chemistry, Paul Scherrer Institute, 5232 Villigen PSI, Switzerland \\ ${ }^{3}$ Department of Physics, Lund University, Lund, Sweden \\ ${ }^{4}$ Swedish Meteorological and Hydrological Institute, Remote Sensing Division, Norrköping, Sweden \\ ${ }^{5}$ Cooperative Institute for Research in Environmental Sciences (CIRES), University of Colorado, Boulder, CO 80309, USA \\ ${ }^{6}$ NOAA Earth Sciences Research Lab, Chemical Sciences Division, Boulder, CO 80305, USA \\ ${ }^{7}$ Institute of Ion and Applied Physics, University of Innsbruck, 6020 Innsbruck, Austria \\ ${ }^{8}$ National Centre for Atmospheric Science, Leeds, UK \\ ${ }^{9}$ Institute for Climate and Atmospheric Science, School of Earth and Environment, University of Leeds, UK
}

Correspondence to: P. Kupiszewski (piotr.kupiszewski@psi.ch)

Received: 4 March 2013 - Published in Atmos. Chem. Phys. Discuss.: 19 April 2013

Revised: 27 October 2013 - Accepted: 12 November 2013 - Published: 19 December 2013

\begin{abstract}
Unique measurements of vertical size-resolved aerosol particle concentrations, trace gas concentrations and meteorological data were obtained during the Arctic Summer Cloud Ocean Study (ASCOS, www.ascos.se), an International Polar Year project aimed at establishing the processes responsible for formation and evolution of low-level clouds over the high Arctic summer pack ice. The experiment was conducted from on board the Swedish icebreaker Oden, and provided both ship- and helicopter-based measurements. This study focuses on the vertical helicopter profiles and onboard measurements obtained during a three-week period when Oden was anchored to a drifting ice floe, and sheds light on the characteristics of Arctic aerosol particles and their distribution throughout the lower atmosphere.

Distinct differences in aerosol particle characteristics within defined atmospheric layers are identified. Within the lowermost couple hundred metres, transport from the marginal ice zone (MIZ), condensational growth and cloud processing develop the aerosol population. During two of the four representative periods defined in this study, such influence is shown. At altitudes above about $1 \mathrm{~km}$, long-range transport occurs frequently. However, only infrequently does large-scale subsidence descend such air masses to become entrained into the mixed layer in the high Arctic, and there-
\end{abstract}

fore long-range transport plumes are unlikely to directly influence low-level stratiform cloud formation. Nonetheless, such plumes can influence the radiative balance of the planetary boundary layer (PBL) by influencing formation and evolution of higher clouds, as well as through precipitation transport of particles downwards. New particle formation was occasionally observed, particularly in the near-surface layer. We hypothesize that the origin of these ultrafine particles could be in biological processes, both primary and secondary, within the open leads between the pack ice and/or along the MIZ. In general, local sources, in combination with upstream boundary-layer transport of precursor gases from the MIZ, are considered to constitute the origin of cloud condensation nuclei $(\mathrm{CCN})$ particles and thus be of importance for the formation of interior Arctic low-level clouds during summer, and subsequently, through cloud influences, for the melting and freezing of sea ice.

\section{Introduction}

The Earth has experienced a statistically significant warming over the past century, mainly as a result of the anthropogenic greenhouse effect (IPCC, 2007). The Arctic is 
a region particularly susceptible to climate change and has warmed at a rate more than twice that of the global average since the mid-1960s (Jeffries and Richter-Menge, 2012). General Circulation Models (GCMs) project that this trend will continue over the course of the 21st century (Holland and Bitz, 2003; ACIA, 2005). Furthermore, summer sea ice extent is decreasing rapidly (Lindsay, 2009), with model simulations projecting that the summer Arctic may become essentially ice-free by or even before the mid-21st century (Holland et al., 2006). Meanwhile, climate models face many issues when projecting Arctic climate; there is a large scatter between model simulations, larger than for any other region on Earth (Raisanen, 2001; ACIA, 2005; Serreze and Francis, 2006). This is likely due to inaccurate descriptions of many of the physical feedbacks and processes within the Arctic climate system (Prenni et al., 2007). Clouds, and related climate feedbacks, are a major cause of uncertainty in climate model projections (Soden and Held, 2006; IPCC, 2007). Clouds are also considered to be one of the most important factors for the surface energy balance in the Arctic (Intrieri et al., 2002).

Clouds both reflect incoming solar radiation and enhance the downward longwave flux by emitting infrared radiation (Ramanathan et al., 1989; Curry et al., 1993; Zhang et al., 1996). As one of the primary determinants of the surface energy balance (Curry and Ebert, 1992; Curry et al., 1993; Mauritsen et al., 2011; Sedlar et al., 2011) they influence the freezing, melting and thickness of the perennial sea ice (Maykut and Untersteiner, 1971; Kay and Gettelman, 2009). The shortwave reflectivity and longwave emissivity of clouds are affected by the number concentration of aerosol particles, which, via their role as cloud condensation nuclei $(\mathrm{CCN})$, facilitate the formation of liquid cloud droplets and determine cloud optical and microphysical properties (Curry et al., 2000; Garrett and Zhao, 2006; Mauritsen et al., 2011), such as albedo, life-time and optical depth.

The limited impact of anthropogenic and continental sources and the resulting low particle concentrations in the summertime Arctic (Bigg et al., 1996; Covert et al., 1996; Leck and Persson, 1996b; Nilsson and Leck, 2002; Heintzenberg et al., 2006; Heintzenberg and Leck, 2012), along with the semi-permanent ice cover, contribute to a complex relationship between aerosol particles, low-level stratiform clouds, radiation and surface albedo (Leck and Bigg, 2007; Sedlar et al., 2011; Heintzenberg and Leck, 2012). The high albedo of sea ice and snow, in combination with low insolation, results in low clouds having a warming effect at the surface during most of the year (Walsh and Chapman, 1998; Intrieri et al., 2002), in contrast to the net global cooling effect (Schneider, 1972; Ramanathan et al., 1989). Furthermore, the semi-permanent ice cover together with the low particle concentrations results in a high sensitivity of the climate system; even small changes in either have a strong impact on the energy balance and summer ice-melt (Leck and Bigg, 2007; Mauritsen et al., 2011; Heintzenberg and Leck, 2012).
Meanwhile, field-study-based analysis of aerosol-cloud interactions in the high Arctic has been severely hampered by difficulties in conducting in situ measurements in a remote and hostile environment. A further complication is the frequently occurring vertical stratification of aerosol and gas concentrations (Bigg et al., 1996, 2001). The formation of aerosol layers is governed by several factors, such as atmospheric mixing and air mass origin over the Arctic, as well as the sources of the precursor gases and aerosol particles themselves. A number of hypotheses regarding the sources of the high Arctic summer aerosol have been put forward and a brief overview follows.

Whilst the regional, and specifically the inner-Arctic, lower troposphere is widely considered to be one of the cleanest in the world in summer (Bigg et al., 1996; Heintzenberg et al., 2006), long-range transport of pollution plumes leads to episodic increases in aerosol concentrations at altitudes above the planetary boundary layer (PBL). According to Pacyna and Oehme (1988), transport of organic pollutants, such as hexachlorocyclohexane, hexachlorobenzene, pentachlorobenzene and $\alpha$-chlordane - mainly from the former Soviet Union, but also from North America and Europe - could be responsible for observed plumes. It has also been suggested that boreal forest fires, occurring predominantly in the summer (Stohl, 2006; Stohl et al., 2006) contribute to the pollution plumes at an altitude of several kilometres (Shipham et al., 1992; Koch and Hansen, 2005; Stohl et al., 2006). In spring, the widespread use of pesticides in Asia, Europe and North America would explain the elevated concentrations of organic compounds measured by Pacyna and Oehme (1988) at a number of Arctic island stations. In contrast to the long-range transport sources described above, Hegg et al. (1995) found that in situ particle production is likely to be taking place aloft. This view was also shared by Garrett et al. (2002) who suggested that homogeneous-bimolecular nucleation of sulphuric acid and water vapour may be responsible for the high concentrations of 20-300 nm diameter particles, which they frequently detected within several hundred metres above low-level stratus clouds. Wiedensohler et al. (1996) presented statistical evidence to suggest that in situ particle production observed in the PBL over the Arctic pack ice area probably originated from higher altitudes. Hence it was speculated that the free troposphere was a possible origin of newly formed particles in the Arctic. Subsequently, Leck and Bigg (1999) used the PBL structure and the vertical distribution of particles during nucleation events to show that, if the newly formed particles did come from above, they had to come from a level less than $140 \mathrm{~m}$ above the surface, and not from the free troposphere. Particles with sizes below $50 \mathrm{~nm}$ in diameter during four Arctic icebreaker expeditions, in the summers of 1991 (Leck et al., 1996), 1996 (Leck et al., 2001), 2001 (Leck et al., 2004; Tjernström et al., 2004) and 2008 (Paatero et al., 2009; Tjernström et al., 2013), have been shown to be produced by in situ fine-particle sources over the high Arctic 
pack ice and possibly have their origin in the open water between ice floes (Leck and Bigg, 1999, 2010; Heintzenberg et al., 2006; Heintzenberg and Leck, 2012).

Due to the usually low concentrations of aerosol particles over the inner Arctic pack ice area in summer, natural surface particle sources have been emphasized as being much more important than transport from continental sources (Leck and Persson, 1996b; Leck and Bigg, 1999, 2005a, 2010; Bigg and Leck, 2001b; Kerminen and Leck, 2001; Leck et al., 2002; Chang et al., 2011). One such local source over the central Arctic Ocean is dimethyl sulphide (DMS), which, via photochemical oxidation and subsequent condensation on pre-existing particles, forms methanesulfonate $\left(\mathrm{CH}_{3} \mathrm{SO}_{3}^{-}\right)$and non-sea-salt sulphate (nss $\mathrm{SO}_{4}^{2-}$ ) (Heintzenberg and Leck, 1994; Leck and Persson, 1996a, b; Quinn et al., 2007). DMS is a gas of phytoplankton origin, and its production and breakdown in the water column must be regarded as a result of complex physiological and ecological interactions, as demonstrated in Leck et al. (1990). Its concentration in water and air has a high seasonal variability, peaking during the summer months as a result of heightened biological productivity, with the highest concentrations being found in open water at the ice margin (Leck and Persson, 1996a, b). The importance of this precursor gas may increase as climate warming over the Arctic proceeds; an increase in summer concentrations of $\mathrm{MSA}^{-}$ and nss $\mathrm{SO}_{4}^{2-}\left(12 \%\right.$ and $8 \% \mathrm{yr}^{-1}$, respectively) has already been measured, based on an analysis of 1976-2008 data from Barrow, Alaska (Quinn et al., 2009).

Organic particulate matter found in the summer Arctic could be created via several pathways. Fu et al. (2009) discovered that oxidation of biogenic volatile organic compounds, such as isoprene, contributed to the aerosol population in the Canadian high Arctic. Another mechanism which has been considered based on observations of particle growth at Summit, Greenland - is the release, and subsequent condensation, of organics from the snowpack (Ziemba et al., 2010). Recent results have clearly demonstrated that biogenic microcolloids shown to be polymer gels (Chin et al., 1998; Orellana et al., 2007), produced by phytoplankton and sea ice algae biological secretions, could constitute an important source of $\mathrm{CCN}$ in the pristine high Arctic summer (Orellana et al., 2011). These results verify past studies of the summer aerosol-cloud relationship over the Arctic pack ice (Bigg and Leck, 2001a, 2008; Leck et al., 2002; Bigg et al., 2004; Leck and Bigg, 2005a, b, 2010). The polymer microgels are emitted directly from open leads via bubble bursting (Norris et al., 2011) and are made up of heat-resistant, highly surface-active and highly hydrated (99\% water) polysaccharide molecules spontaneously forming three-dimensional networks inter-bridged by divalent ions $\left(\mathrm{Ca}^{2+} / \mathrm{Mg}^{2+}\right)$, to which other organic compounds, such as proteins and lipids, are readily bound (Decho, 1990).
The variety of local and long-range transport aerosol sources impacting different atmospheric vertical layers clearly suggests that predictions of cloud properties based on surface aerosol concentration measurements are both highly complex and uncertain and are critically dependent on the boundary layer evolution and atmospheric mixing between the surface and aloft. Consequently, in order to better understand low-level stratiform cloud formation over the pack ice in summer, emphasis should be placed on vertical profiling of the atmosphere. Such an approach provides valuable information on the importance of the respective aerosol sources as $\mathrm{CCN}$ precursors, and on the mechanisms via which aerosol particles are transported vertically and entrained within lowlevel stratiform clouds.

In this context, the vertical profiles of size-resolved aerosol particles and meteorological data, obtained with a helicopter during the Arctic Summer Cloud Ocean Study (ASCOS) (www.ascos.se) in 2008 and presented in this paper, constitute a unique and important data set. It should be noted that there are a number of existing publications on vertical aerosol measurements over the Arctic using aircraft (e.g. Yamanouchi et al., 2005; Engvall et al., 2008), as well as unmanned aerial systems (Bates et al., 2013). However, these studies have predominantly taken place at lower latitudes than the ASCOS study, where additional atmospheric mechanisms and processes are of importance. Only two other campaigns have conducted similar (albeit less comprehensive) measurements of the vertical stratification of aerosol, and gas phase DMS, over the high Arctic north of $80^{\circ}$ : the Arctic Ocean Experiment 1996 (AOE-96) (Bigg et al., 2001; Leck et al., 2001) and the Arctic Ocean Experiment 2001 (AOE2001) (Lundén et al., 2010), with the latter also including acetonitrile measurements. The present study focuses on 38 of the vertical helicopter profiles, obtained during a threeweek period while the Swedish icebreaker Oden was anchored to a drifting ice floe within the high Arctic pack ice area. The helicopter aerosol profiles are analysed in conjunction with meteorological data and onboard particle measurements, with simultaneous profiling of DMS and acetonitrile (used as tracers for air that has been in contact with sea and biomass burning, respectively), with the aim of establishing the characteristics of Arctic aerosol particles and their distribution throughout the lower atmosphere. In particular, the vertical stratification of aerosol particles and its dependence, or lack thereof, on local sources, aerosol processing, transport pathways and atmospheric mixing are presented.

\section{Geographical setting, instrumentation and methods}

\subsection{The Arctic Summer Cloud Ocean Study 2008 expedition}

The data analysed in this study and presented in this paper were obtained during ASCOS in 2008, an Arctic cruise on 


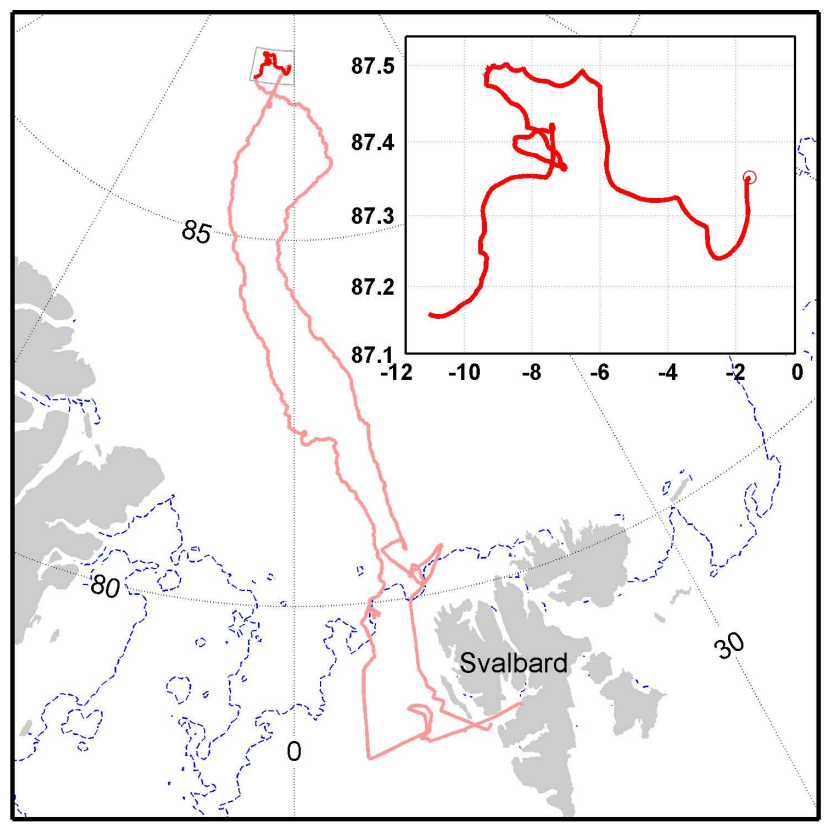

Fig. 1. Oden icebreaker track (pink) with the ice-drift path enlarged in the insert marked red. The circle indicates the start of the icedrift. The observed ice edge on 12 August 2008 is given by the thin blue line.

board the Swedish icebreaker Oden, carried out as part of the International Polar Year (IPY) 2007-2008. The expedition was highly interdisciplinary, with a plethora of measurements being conducted in the fields of marine biology, atmospheric chemistry, oceanography and meteorology. The overriding aim of the expedition was improving our understanding of low-level stratiform cloud formation and evolution in summer over the central Arctic Ocean (north of $80^{\circ}$ ), in order to clarify processes between the surface, cloud layers and free atmosphere. One particular focus was placed on the connections between marine microbiological productivity (as it is most active during this period), $\mathrm{CCN}$ and cloud formation.

The expedition departed from Longyearbyen, Svalbard on 2 August 2008 (day of year, DoY, 215; note the leap year), and headed north for the pack ice of the central Arctic Ocean (see Fig. 1). On 12 August (DoY 225) Oden was anchored to a large ice floe, slightly north of $87^{\circ} \mathrm{N}$, and proceeded to drift with the ice floe for the following three weeks (referred to henceforth as the ice drift), until midnight between 1 and 2 September (DoY 245-246). For further cruise details see Paatero et al. (2009) and Tjernström et al. (2013).

\subsection{Instrumentation}

\subsubsection{Helicopter-based particle counters}

Two condensation particle counters (CPCs) placed on board the helicopter (Fig. 2) were employed in parallel in order to measure the concentration of submicrometre aerosol parti-

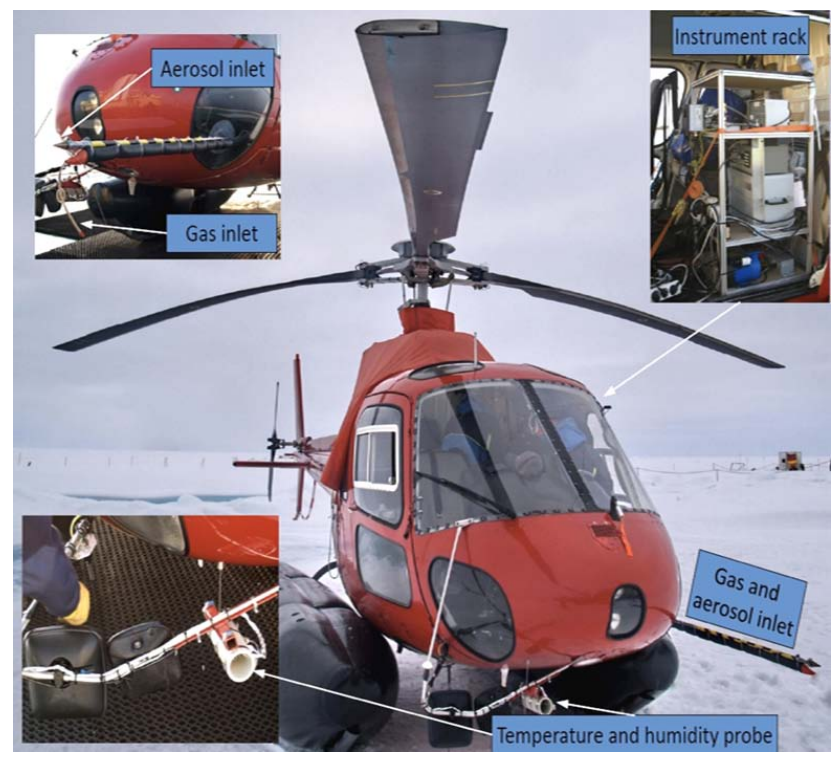

Fig. 2. The ASCOS 2008 expedition helicopter with instrument and air inlet locations.

cles. Each of the CPCs measured the integral number concentration of particles with a diameter over a certain threshold. Details of the operating principles can be found in Hermann and Wiedensohler (2001). The two CPCs used were the TSI model 3025 Ultrafine Condensation Particle Counter (UCPC) and the TSI model 7610 CPC. The UCPC detected particles larger than $3 \mathrm{~nm}$ in diameter, whilst the CPC detected particles larger than $14 \mathrm{~nm}$ in diameter. The upper detection limit of the CPCs in the system was approximately $3 \mu \mathrm{m}$. In order to verify the functioning of the CPCs, CPC concentrations measured whilst the helicopter was on deck were compared with those obtained using the twin differential mobility particle sizer (TDMPS) on board Oden. The counts agreed to within $\pm 20 \%$.

The Compact Lightweight Aerosol Spectrometer Probe (CLASP) optical particle counter (OPC), developed at the University of Leeds, is theoretically able to determine the concentration of aerosols between $300 \mathrm{~nm}$ and $30 \mu \mathrm{m}$ in diameter. However, due to the inlet and subsequent tubing losses in our experiment, few particles larger than the $50 \%$ cut-off diameter of $9.5 \mu \mathrm{m}$ reach the instruments. The temporal resolution of the instrument is $10 \mathrm{~Hz}$, making it well suited for aircraft sampling. In-depth information about the workings of the CLASP is given by Hill et al. (2008). The CLASP OPC and the CPCs were placed on board the helicopter in the left back seat, on a common instrumentation rack (Fig. 2).

By employing two CPCs with different threshold diameters and subtracting the integral number concentration of the CPC from that of the UCPC, the number concentration of particles in the diameter size range 3-14 nm, (approximately representing the ultrafine particle concentration) was 
obtained. Particles in this size range will be referred to as $D_{3-14}$. By subtracting the integral number concentration of the OPC instrument from that of the CPC, the number concentration of particles in the diameter size range $14-300 \mathrm{~nm}$, henceforth referred to as $D_{14-300}$, was obtained. Whilst this size range encompasses both Aitken-mode and smaller accumulation-mode particles, by number it mainly represents the Aitken mode (due to the generally much higher number concentrations of smaller particles). Finally, the number concentration of particles larger than $300 \mathrm{~nm}$, representing larger accumulation-mode particles, was measured by the OPC and these particles will be referred to as $D_{>300}$.

The aerosol particle number concentration data from both the CPC and OPC counters has been adjusted for standard temperature $\left(0^{\circ} \mathrm{C}\right)$ and pressure $(1013.25 \mathrm{hPa})$, as defined by NIST (the National Institute of Standards and Technology), and has been provided at a frequency of $1 \mathrm{~Hz}$. Furthermore, the following corrections were applied to the instrumentation data: first, adjustments were made to the UCPC data in order to account for changes in the amount of air pumped by the instrument with altitude. This was necessary as the air flow is controlled by a pressure sensor, with the pressure drop over a capillary kept constant over time. Therefore, the volume flow rate increases with height (as density decreases), leading to excessively high concentrations being recorded at greater altitudes (almost linearly up to $6 \%$ error at $3500 \mathrm{~m}$ ). Second, both the UCPC and CPC concentrations were corrected for actual flow readings done at intervals between the flights. Air flow in the CPC was controlled using a critical orifice, with a constant volume flow when the temperature of the orifice and air stream remains constant, which was approximately the case (potential errors are relatively low at $3 \%$ for a $10 \mathrm{~K}$ difference in temperature).

Data collected from the CLASP instrument have been corrected for losses through the sample tubing based on tubing length, as well as the number and angle of bends (tubing dimensions as described in Sect. 2.2.4). To adjust the data for variations in relative humidity $(\mathrm{RH})$ during sampling, the following steps were taken: the outside temperature and $\mathrm{RH}-$ as measured by a PTU300 sensor (see Sect. 2.2.3) - were taken as the starting conditions of the sampled air. The $\mathrm{RH}$ at the entrance of the CLASP unit was then calculated (generally around $20 \%$ ), based on the starting conditions and an assumed cabin temperature of $20^{\circ} \mathrm{C}$, and the data were then corrected to an $\mathrm{RH}$ of $0 \%$ (dry size).

However, neither the CPC nor the OPC data have been corrected for losses due to inlet transmission efficiency depending on variations in flight speed and orientation. Furthermore, counting errors could occur due to changes in the sample temperature during transmission through the sample lines. As the sample is transferred from the colder ambient environment to the warmer helicopter interior, evaporation of volatile particle constituents could take place, resulting in a decrease in the size of the particles, possibly to below the lower detection limit of the instruments; such a process would result in undercounting of the total particle number. The data have not been corrected to account for this possibility.

From the ship, the helicopter was flown perpendicular to the wind direction, and turned slightly upwind before the return flight. This method was chosen in order to ensure sampling of unpolluted air, as well as not to disturb the measurements on board the ship.

\subsubsection{Helicopter-based gas-phase DMS and acetonitrile}

A custom-built, portable air-sampling unit was installed in the helicopter for eight flights for off-line volatile organic compound (VOC) analysis. The heated VOC inlet (1/4" Silcosteel ${ }^{\circledR}$; Restek Corporation, Bellefonte, PA, USA) was mounted to the aerosol inlet, protruding $1 \mathrm{~m}$ from the front of the helicopter (Fig. 2). A pump (KNF Neuberger, Balterswil, Switzerland) continuously drew ambient air through a manifold, to which eight SilcoCan ${ }^{\circledR}$ air monitoring canisters (6 L volume; Restek Corporation, Bellefonte, PA, USA) were connected via shut-off valves. A pressure gauge recorded the pressure in the manifold.

Before each flight, all SilcoCans were preconditioned at $50^{\circ} \mathrm{C}$ by evacuation, refilled with VOC-free air, and finally evacuated to a pressure below $2 \mathrm{mbar}$ before the sampling unit was strapped into the helicopter. Air samples were collected at different heights at the discretion of the flight scientist by manually closing the pump valve and opening an individual SilcoCan. The filling took about $30 \mathrm{~s}$ (heightdependent) during which the helicopter was flown at a constant elevation. After sampling, the SilcoCan was shut off and the pump valve was re-opened to keep the inlet purged with ambient air.

After each flight, the portable air sampling unit was immediately taken to the VOC laboratory on board the icebreaker Oden. The SilcoCans were heated to $50{ }^{\circ} \mathrm{C}$ and connected to the ship-based high resolution proton transfer reaction time of flight mass spectrometer (PTR-TOF-MS) by a heated Silcosteel coated inlet capillary. The PTR-TOF-MS sampled the conserved air for about $30 \mathrm{~min}$ for each individual canister. The long sampling time allowed for a limit of detection in the low ppt(v) range for most VOCs. All SilcoCans were typically analysed within $12 \mathrm{~h}$ after the end of the flight.

Dynamic dilution of a $\sim 1 \mathrm{ppm}(\mathrm{v})$ calibration gas standard (Apel-Riemer Inc., USA), containing acetonitrile, acetone and 14 other VOCs (but not DMS) was used for intermittent sensitivity calibrations of the PTR-TOF-MS. The accuracy of the calibrations using the gas standard VOCs in combination with the dilution setup is estimated to be $13 \%$ or better. For DMS, a liquid calibration unit (LCU) was used for cross-calibration with acetone. For the LCU, there is additional inaccuracy due to the mixing of acetone and DMS in a Hamilton ${ }^{\circledR}$ syringe. The accuracy of the DMS calibration is estimated to be better than $20 \%$. Details about the PTR-TOFMS technology and performance are described elsewhere 
(e.g. Jordan et al., 2009; Graus et al., 2010). The applied data reduction and peak identification methods are described by Graus et al. (2010) and Müller et al. (2010).

\subsubsection{Helicopter-based meteorological measurements}

Meteorological measurements recorded during profile flights included atmospheric pressure $(\mathrm{hPa})$, air temperature $\left({ }^{\circ} \mathrm{C}\right)$ and relative humidity (\%). Within the cabin, a Vaisala Combined Pressure, Temperature and Humidity Transmitter (PTU300) was mounted on the instrument rack which also housed the logging laptop and aerosol counter instruments (Fig. 2). The PTU300 temperature and humidity sensor was mounted within an open cylindrical PVC housing near the front of the helicopter, acting to minimise sensor heating by solar radiation as well as providing open ventilation for airflow across the sensor. Three thermocouples were also mounted equidistantly within the PVC cyclinder for additional temperature measurements; these three sensors showed good agreement (with very little intra-variance) and were thus averaged for temperature profile analysis. The thermocouple wires were wrapped in an aluminium heat shield, extending from the sensor location back to the helicopter cabin, to minimize solar heating. A fourth thermocouple was mounted near the aerosol inlet to measure the ambient temperature of air entering the inlet. Analysis of these temperatures showed a warm bias on the order of $0.5-1{ }^{\circ} \mathrm{C}$, indicating solar heating of the thermocouple; therefore temperatures from the fourth thermocouple were dismissed from the analysis of thermodynamic profiles. The PTU300's pressure sensor was connected to the helicopter's static pressure port. Heights were calculated using the pressure and temperature measurements following the hypsometric equation.

All meteorological variables were logged at $2-3 \mathrm{~Hz}$, from which $1 \mathrm{~Hz}$ measurements were produced to coincide with the temporal sampling of aerosol measurements. Sensor accuracy specifications from the PTU300 are reported as $\pm 0.15 \mathrm{hPa}, \pm 1.7 \%$ (for $90-100 \% \mathrm{RH}$ range) and $\pm 0.3{ }^{\circ} \mathrm{C}$ for pressure, relative humidity and temperature, respectively. The thermocouple temperature accuracy was specified as $\pm 0.5^{\circ} \mathrm{C}$. Corrections to meteorological variables based on helicopter flight speed were deemed unnecessary, as the science flights were flown at airspeeds with which the sampling frequency was determined adequate to capture thermodynamic fluctuations in the lower atmosphere.

\subsubsection{Configuration of the helicopter aerosol sampling inlet}

The instrumentation rack in the helicopter was installed in the port side back passenger seat. The rack contained the CPCs, OPC, PTU300, the logging computer and the airflow pump. An isokinetic inlet extended $1 \mathrm{~m}$ in front of the helicopter cabin with a sampling true air speed of $19 \mathrm{~ms}^{-1}$, maintained manually by the pilot. Stainless steel tubing (in- ner diameter $12 \mathrm{~mm}$ ) on the floor of the cabin connected the inlet to the instrumentation rack (see Fig. 2). Two $45^{\circ}$ bends were used in order to reach the rack. The total inlet length (into the OPC) was $3.05 \mathrm{~m}$. The total flow in the inlet tubing was $10 \mathrm{~L} \mathrm{~min}^{-1}$. The CPCs were installed above the OPC ( 0.25 and $0.55 \mathrm{~m}$ for the UCPC and the CPC, respectively), with a tee (one $90^{\circ}$ bend) from the main inlet line and a second $90^{\circ}$ bend in the line for each CPC. Precisely after takeoff (and away from local pollution), the particle concentrations were compared to those measured by instrumentation onboard Oden. During flights in clean air (for example, measured total particles $<1 \mathrm{~cm}^{-3}$ ) it was verified that no significant downwash of particles from the helicopter rotor reached the inlet.

\subsubsection{Ship-based aerosol physical characterization resolved over size}

The ambient aerosol was sampled via a $\mathrm{PM}_{10}$-inlet mast setup on a laboratory container on the fourth deck of Oden at about $25 \mathrm{~m}$ above sea level. Size distributions of particles with mid-diameters from $3 \mathrm{~nm}$ to $800 \mathrm{~nm}$ were continuously monitored using the TDMPS. Further details of the $\mathrm{PM}_{10}$ inlet and the TDMPS system can be found in Heintzenberg and Leck (2012).

\subsubsection{Meteorological observations}

General meteorology was observed both by two weather stations on board Oden and from a micrometeorological site deployed on the ice; the measurements included air and surface temperatures, wind speeds and visibility. In addition, radiosoundings of pressure, temperature, humidity and wind speed through the entire troposphere were launched at sixhourly intervals from the helipad of Oden.

Remote sensing instruments placed on board Oden were used to infer cloud micro- and macrophysical parameters, including cloud base and top height, as well as the atmospheric temperature profile. Several cloud ceilometers provided cloud base information, while the cloud top data was obtained from the $35 \mathrm{GHz}$ K-band MilliMeter Cloud Radar (MMCR), based on a vertical-pointing, single-polarization Doppler technique. The vertical resolution of the MMCR is $45 \mathrm{~m}$, whilst its vertical coverage stretches from $100 \mathrm{~m}$ to 15 kma.g.l. (Moran et al., 1998). Finally, a $60 \mathrm{GHz}$ passive scanning radiometer located on the right-hand side of the ship (over the ice pack) was employed to measure the temperature profile of the atmosphere up to $1.2 \mathrm{~km}$, thus providing information about the height of the main inversion base (observations obtained for $98 \%$ of the ice drift period; M. Tjernström, personal communication, 2012). The resolution of the scanning radiometer is approximately $15-300 \mathrm{~m}$, degrading upwards, whilst its root mean square (rms) accuracy is better than $1^{\circ} \mathrm{C}$ up to a height of ca. $800 \mathrm{~m}$ (Westwater et al., 1999). Due to the decline in resolution and accuracy at 
greater altitudes, retrieving inversions above $500 \mathrm{~m}$ a.g.l. becomes increasingly difficult. The retrieval algorithm requires a "first-guess" profile; here interpolated profiles from the sixhourly soundings are applied. This implies that with increasing altitude above $\sim 800 \mathrm{~m}$, the observations gradually lose information beyond that of radiosonde interpolation. Both the MMCR and scanning radiometer were designed by the Earth System Research Laboratory (ESRL) of the National Oceanic and Atmospheric Administration (NOAA) in Boulder, Colorado.

\subsection{Air mass trajectories and time spent over the pack ice}

In order to establish the origin of inflowing air masses, threedimensional 5- and 10-day backward air parcel trajectories were calculated. The receptor point was set at $100 \mathrm{~m}$ altitude (for period-based analysis) or at the altitude of the observed plume when investigating specific long-range transport events. The Hybrid Single Particle Lagrangian Integrated Trajectory Model (HYSPLIT) (Draxler and Rolph, 2011; Rolph, 2011) was used for the trajectory calculations based on data from the Global Data Assimilation System (GDAS) of the National Weather Service's National Center for Environmental Prediction (NCEP). Vertical motion in the trajectory runs was calculated using the model's vertical velocity fields.

Back trajectories have several sources of uncertainty; the spatial and temporal resolution of the gridded meteorological data that is used and the fact the stochastic motions such as, for example, turbulence in the PBL, cannot be recovered by the backwards calculations. This uncertainty generally grows with the length of the trajectory, but may also be smaller or larger for different episodes. For example, transport within a single air mass is likely more reliable, while transport in the vicinity of strong gradients, such as frontal zones, can create bifurcations and should be considered with care.

The time spent over the pack ice by the air mass since last contact with open sea, referred to as days over ice (DOI), was calculated for the purposes of ASCOS as in Nilsson (1996). This calculation uses the HYSPLIT back trajectories in combination with maps of sea-ice distribution. The latter were created based on data from the National Snow and Ice Data Center (NSIDC), Boulder, United States, obtained by the AMSR-E sensor on board the Aqua satellite, and the final analysis was conducted at the University of Bremen.

\section{Observations of meteorological conditions during the ice drift}

The general meteorological conditions encountered during ASCOS, and in particular those during the ice drift phase, are summarized in Tjernström et al. (2012), while Sedlar et al. (2011) describes the evolution of the surface energy

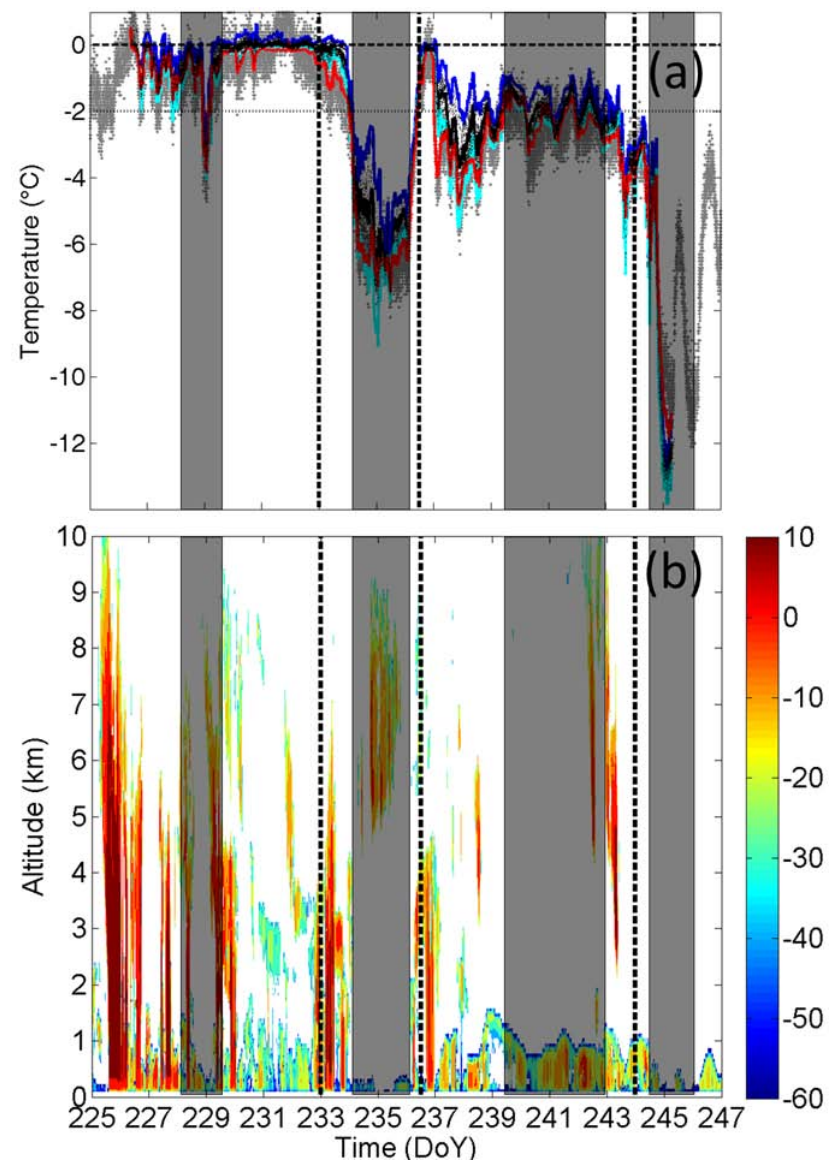

Fig. 3. (a) Time series of several different temperature $\left[{ }^{\circ} \mathrm{C}\right]$ observations: air temperature on board Oden (gray dots); snow surface temperatures at 10 different locations (black dots); mean, plus and minus 2 standard deviations (black, blue and red) of the ten snow surface temperature observations; and air temperature $20 \mathrm{~cm}$ over the surface (cyan). (b) Time-height cross-section of radar reflectivity $\left[\mathrm{dBZ}_{\mathrm{e}}\right]$; from the MMCR cloud radar deployed on board the icebreaker Oden. Being primarily sensitive to hydrometeor size, the deepest red colours represent large ice crystals in, for example, snow or cirrus clouds, while blue and green shading is representative of cloud droplets and rain or drizzle. The plots show roughly the time period of the ice drift; the vertical dashed lines indicate the time regimes discussed in Sect. 3, while the shaded areas indicate the specific periods discussed in this paper.

budget, cloud radiative forcing and the transition from summer melt to autumn freeze up.

Figure 3 illustrates the more general conditions during the ice drift, using several different temperature observations (Fig. 3a) and the reflectivity from the MMCR deployed on Oden $\left(\mathrm{dBZ}_{\mathrm{e}}\right.$; Fig. 3b). Cloud radar reflectivity is primarily sensitive to hydrometeor size, so generally the warmest (red) colours indicate falling snow, while clouds or liquid precipitation are indicated by the cooler (blue and green) shades.

The general conditions were divided into four distinct regimes by Sedlar et al. (2011) (Fig. 3, dashed black lines). 
a)

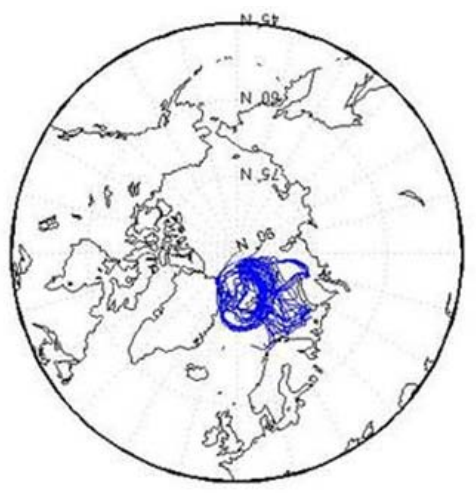

c)

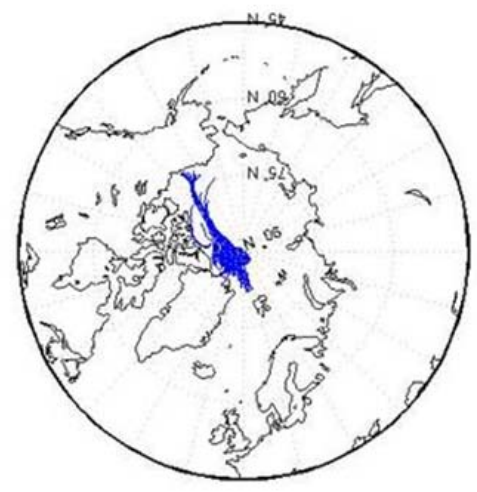

b)

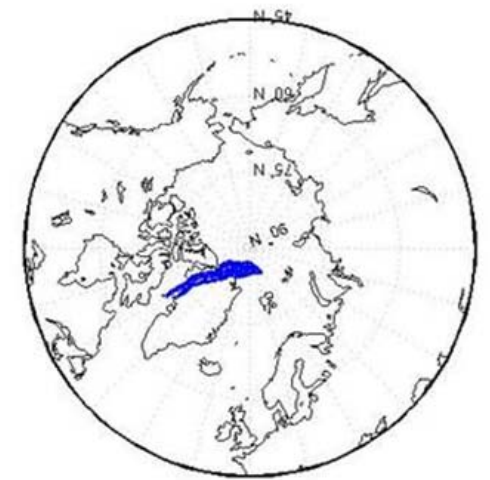

d)

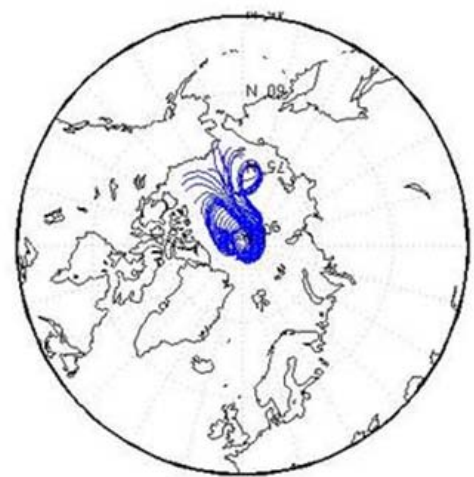

Fig. 4. Air mass trajectory probability source contribution function calculated for $100 \mathrm{~m}$ altitude: (a) period 1 , (b) period 2 , (c) period 3 and (d) period 4 .

During the first of the main regimes defined by Sedlar et al. (2011), atmospheric conditions were highly variable in association with passing synoptic-scale weather systems; large vertical structures in the radar reflectivity shown in Fig. $3 b$ indicate deep frontal clouds and their corresponding precipitation. Typical for melt-season conditions (Fig. 3a), the near-surface temperature remained close to $0^{\circ} \mathrm{C}$ except for during a few brief periods. This regime ended around DoY 233 and was followed by a shorter regime with significantly less clouds and lower temperatures. Temperatures fell to $-6^{\circ} \mathrm{C}$ while the clouds were predominantly fog and low clouds; the high cloud layer in the radar image was in fact an optically thin cirrus layer composed of relatively large ice crystals.

Following this, the third regime was dominated by a higher surface pressure that lasted about a week, with a persistent layer of stratocumulus clouds and very little high clouds (Fig. 3b). Except at the very beginning, when a weather system passed, near-surface temperatures were now semistationary around $-2{ }^{\circ} \mathrm{C}$, near the freezing temperature for saline ocean water $\left(-1.8^{\circ} \mathrm{C}\right.$ with a normal salinity of 35 parts per thousand, Barry et al., 1993), but with a pronounced diurnal cycle. Finally, on 31 August (DoY 245), the positive (warming) radiative forcing from the clouds vanished as the stratocumulus dissipated (Fig. 3b), and the temperature immediately dropped to below $-10^{\circ} \mathrm{C}$ (Fig. 3a), initiating the fourth regime. Any remaining open water froze, and the autumn freeze-up was established whereby temperatures remained below the freezing point of the ocean (Sedlar et al., 2011). Clouds were again dominated by patchy fog and stratus clouds with no upper level clouds; the near-surface temperature fluctuated between -4 and $-12{ }^{\circ} \mathrm{C}$ in response to cloudy and clear episodes (Sedlar et al., 2011). Finally, nearsurface wind speeds were relatively low $\left(<\sim 6 \mathrm{~ms}^{-1} 70 \%\right.$ of the time; Tjernström et al., 2012).

Definitions of study periods within each of the regimes. The air mass origin and transport over the pack ice, computed from backward air trajectories for a receptor point of $100 \mathrm{~m}$, show large variability. Clustering of the trajectories (Fig. 4) allows for identification of periods with similar air sources. Based on the different meteorological regimes discussed in Sedlar et al. (2011), in combination with the trajectory clusters, four periods with common meteorology and prevailing air-mass origin are selected for in-depth analysis of vertical aerosol profiles. Such an approach is necessary in order to address the large variations in meteorological conditions, including inversion base height, cloud height and atmospheric turbulence, as well as the changing origin of the air mass itself. The four shorter periods selected in this study, shown by the shaded areas in Fig. 3, have been named 

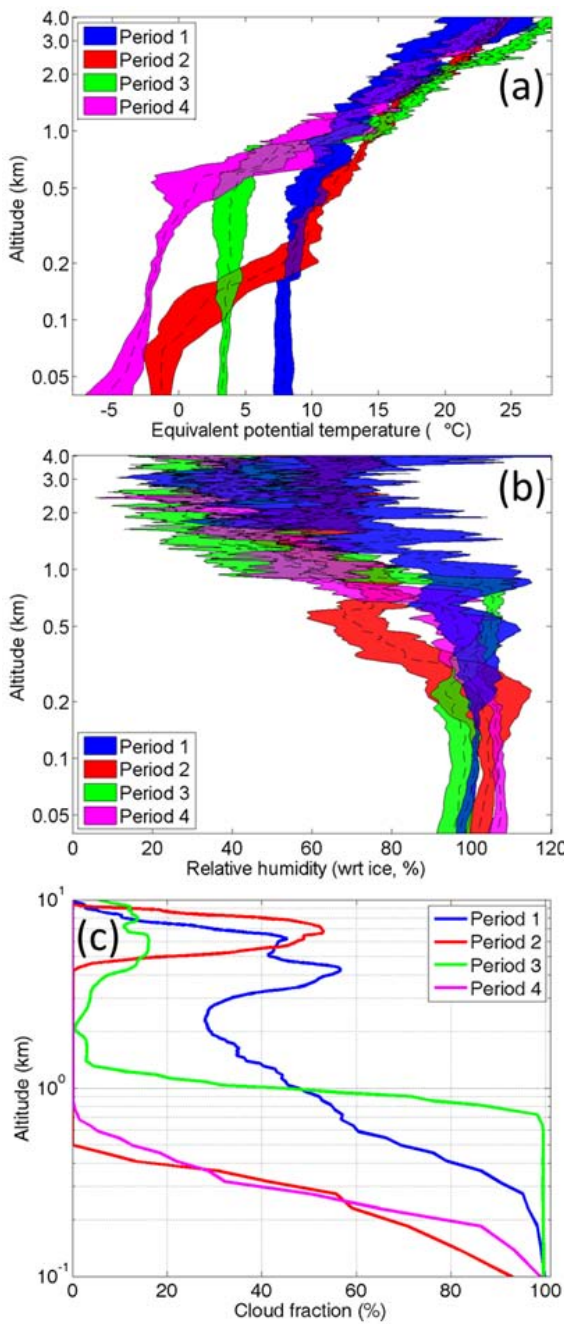

Fig. 5. Top two graphs show the median (thin dotted line) and the 25- to 75-percentile intervals (shading) for (a) the equivalent potential temperature and (b) relative humidity with respect to ice for the four periods discussed in this paper, (c) shows the median cloud fraction as a function of height. Note the logarithmic vertical axis and the higher top in the cloud fraction panel.

the melt (period 1: 05:00 15 August-14:00 UTC $16 \mathrm{Au}$ gust, DoY 228.208-229.583), the cold spell (period 2: 03:00 21 August-02:00 UTC 23 August, DoY 234.125-236.083), the preconditioning (period 3: 01:00 27 August-11:00 UTC 30 August, DoY 240.042-243.458) and the freeze-up (period 4: 15:00 31 August-04:00 UTC 2 September, DoY 244.632-246.167), and are characterized in greater detail in Sect. 4.

During the first period, the air mass reaching $100 \mathrm{ma.g} .1$. at the position of the icebreaker originated in the Greenland, Barents and Kara seas (Fig. 4a). Based on the air mass trajectories and sea ice distribution, the DOI of the air mass was relatively short (ca. 1.2 days). The trajectory clusters for the 2 nd period (Fig. $4 \mathrm{~b}$ ) showed air mass origin from north- ern Greenland. However, as the trajectories never touch open sea before arriving at the position of the icebreaker, no DOI could be estimated. Air mass trajectories for the third period (Fig. 4c) show prevailing flow from the direction of the Beaufort Sea. The DOI of the air mass during the 3rd period was 6.7 days. During the fourth period, air mass flow was largely from over the pack ice (Fig. 4d) with a DOI of 8.2 days and from the direction of the Laptev and East Siberian seas towards the end of the period but still with no contact with open sea.

Figures 5 and 6 illustrate some of the meteorological conditions for the periods studied in detail in this paper. Figure 5a shows the median and 25- to 75-percentile intervals of the profiles of the equivalent potential temperature ${ }^{1}, \Theta_{\mathrm{e}}$, while Fig. $5 \mathrm{~b}$ shows the same for the relative humidity with respect to ice, $\mathrm{RH}_{i}$, both taken from six-hourly radiosoundings. Figure $5 \mathrm{c}$ shows profiles of the median cloud fraction. Figure 6a-d shows time-height cross-sections of temperature $\left({ }^{\circ} \mathrm{C}\right)$ for each of the periods from the scanning microwave radiometer; the start times of individual helicopter flights are marked by diamonds on the time axis.

\section{Vertical aerosol and gas-phase profile characteristics}

\subsection{General vertical structure characteristics during the ice drift}

The summer Arctic PBL is typically a well mixed shallow layer at the surface, capped by a temperature inversion. The inversion may at times be strong, such as when there is substantial advection of warmer air from lower latitudes, while the free troposphere is stably stratified. This structure is in contrast to that of more southerly latitudes, where deep convection could enhance mixing across the whole troposphere. The PBL vertical structure during the ice drift, was characterized by a generally shallow wind-shear driven surface PBL topped by a cloudy layer, which generates turbulence by buoyancy from longwave radiative cloud-top cooling. Depending on the relative strength of the two mixing processes, and the altitude to the cloud base, this system sometimes appears as one single shallow and well-mixed PBL, with depths usually below $\sim 300 \mathrm{~m}$, and sometimes separates into two decoupled turbulent layers, one associated with the surface and one with the cloud layer (Tjernström, 2007; Shupe et al., 2013). In the latter case, the layers are separated either by a weak inversion or sometimes just by a nearneutrally stratified layer, and can be quite deep, up to $\sim 1 \mathrm{~km}$

${ }^{1} \Theta_{\mathrm{e}}=\Theta+\frac{L \Theta}{c_{\mathrm{p}} T} q$, where $\Theta$ is the potential temperature defined as $\Theta=T(p / 1000)^{\frac{R_{\mathrm{d}}}{c_{\mathrm{p}}}}, T$ is the temperature, $p$ is the pressure, $R_{\mathrm{d}}$ and $c_{\mathrm{p}}$ are the gas constant and heat capacity of dry air, respectively, $L$ is the latent heat of vaporization and $q$ is the specific humidity. Note that in the definition of $\Theta_{\mathrm{e}}$ for unsaturated conditions, the temperature $(T)$ is evaluated at the lifting condensation level. 
or more (Tjernström et al., 2012). Consequently, the stratification of the PBL is dominated by moist adiabatic stratification (Fig. 5b), but closer to the surface it is sometimes more stably stratified (Tjernström, 2005); this is when the mixing from cloud-top cooling does not reach the surfacebased PBL. This neutral stability is also visible in the potential temperature probability profile from the ASCOS 2008 expedition, with near-constant potential temperature below approximately $500 \mathrm{~m}$ altitude (periods 1,3 in Fig. 5a).

Low clouds dominated the generally cloudy conditions during the ice drift (Sedlar et al., 2011), with cloud bases often below $100 \mathrm{~m}$ (Fig. 5c). The presence of fog was also common. Cloud tops varied from several hundred metres to $\sim 1 \mathrm{~km}$, with cloud thickness very rarely exceeding $1 \mathrm{~km}$, except for in frontal clouds associated with weather systems. Visibility was bimodal; $<1 \mathrm{~km}$ and $>20 \mathrm{~km}$ under even very low clouds (in the absence of snow fall) (Tjernström et al., 2012). Contributing to these conditions was an essentially unlimited source of water vapour, which was made available due to open leads, melt ponds and snow, as well as synoptic advection associated with intermittent frontal passages. As a consequence, RH was consistently close to $100 \%$ - with respect to (wrt) water when the temperature was close to zero, and with respect to ice when the temperature was below (in fact very often $>100 \%$ wrt ice, see Fig. 5b). Additionally, specific humidity often increased with height over the PBL-capping inversion. This is a condition that rarely occurs elsewhere but is frequent in the Arctic (Sedlar et al., 2012) and implies that entrainment across the inversion is a moisture source for the boundary layer rather than a sink.

\subsection{General aerosol characteristics over the ice drift}

The general structure of the vertical aerosol number concentration profiles based on data compiled from 38 helicopter flights conducted during the ice drift period can be summarized as follows: median $D_{3-14}$ aerosol particle concentrations were highest near the surface (Fig. 7, left panel), growing from ca. $30 \mathrm{~cm}^{-3}$ at the near-surface, to a maximum of ca. $70 \mathrm{~cm}^{-3}$ at a little over $60 \mathrm{ma}$ a.g.1. Median concentration declines sharply over the next ca. $100 \mathrm{~m}$ and remains constant with height to approximately $700 \mathrm{ma}$ a.g.l. It then increases gradually up to $3000 \mathrm{~m}$ altitude, with a large variability between ca. $2300 \mathrm{~m}$ and $2900 \mathrm{~m}$. However, it should be noted that due to the limited number of flights at these altitudes (seven flights at altitudes over $2000 \mathrm{~m}$ ), the statistics are less likely to be representative of the whole population, and the features observed become less significant at higher altitudes.

Whilst $D_{3-14}$ particle concentrations were mostly low, with minimum concentrations of a couple particles $\mathrm{cm}^{-3}$, extremely high concentrations were episodically observed, particularly within the near-surface layer, with maximum concentrations on the order of $10^{5} \mathrm{~cm}^{-3}$. As ultrafine particles have a very short residence time (less than one day for particles with diameters smaller than $10 \mathrm{~nm}$ ), resulting from rapid diffusion to cloud particles and an efficient coagulation sink (Wallace and Hobbs, 2006), an important point to make is that the $D_{3-14}$ particles must represent in situ local production.

Meanwhile, median $D_{14-300}$ particle concentrations were between 50 and $85 \mathrm{~cm}^{-3}$ within the lower $500 \mathrm{~m}$ of the atmosphere, increasing in number to over $100 \mathrm{~cm}^{-3}$ and rising occasionally to ca. $200 \mathrm{~cm}^{-3}$ within the free troposphere (Fig. 7, middle panel). Concentrations in both the $D_{3-14}$ and $D_{14-300}$ size ranges varied tremendously, by as much as five orders of magnitude. The variability was highest in the lowermost $100 \mathrm{~m}$, decreasing by 1-2 orders of magnitude at higher altitudes. $D_{>300}$ particle concentrations were ca. $1 \mathrm{~cm}^{-3}$ within $1 \mathrm{kma}$ a.l. (Fig. 7, right panel), increasing by several factors, and sometimes by as much as an order of magnitude, at certain heights within the free troposphere. This distribution pattern was different to that of $D_{3-14}$ particles - with variability and increased concentrations mainly aloft, within the free troposphere, as opposed to the high variability and episodically high concentrations in $D_{3-14}$ particles observed within the lowermost $100 \mathrm{~m}$. Based on air mass trajectory analysis, the higher concentrations in the free troposphere are believed to be a result of long-range air transport from Siberia and the Canadian Arctic Archipelago, explaining the difference in vertical distribution relative to $D_{3-14}$ particles, which are considered to be produced locally from a surface source. Additionally, strong gradients in $D_{>300}$ concentrations tend to coincide with the geometric boundaries of the typical lower troposphere cloud layers observed during ASCOS. Since helicopter flights generally were limited to the clear, sub-cloud layers, these profiles suggest that cloud processing may exhibit a dominant control on the larger aerosol particles.

\subsection{General gas phase DMS and acetonitrile characteristics over the ice drift period}

Measurements of DMS (derived from phytoplankton in the upper ocean) and acetonitrile (a specific tracer for biomass burning) concentrations, taken during eight helicopter flights, showed differing behaviour of the two gas-phase constituents with altitude. DMS concentrations (Fig. 8, left panel) showed large variability in the near-surface layer, with observations between 2 and $123 \mathrm{ppt}(\mathrm{v})$ within the lowermost $200 \mathrm{~m}$. The median (mean) value within this layer was 7 (34) ppt(v). Between 200 and 1000 ma.g.l., the median concentration increased to $11 \mathrm{ppt}(\mathrm{v})$; however, the mean decreased to $22 \operatorname{ppt}(\mathrm{v})$. Above 1000 ma.g.l., both median and mean concentrations decreased, to $4 \operatorname{ppt}(\mathrm{v})$ and $5 \mathrm{ppt}(\mathrm{v})$ respectively, with almost all measurements below $10 \mathrm{ppt}(\mathrm{v})$. Meanwhile, acetonitrile concentrations showed somewhat less variability than DMS within the lowermost $200 \mathrm{~m}$, but greater scatter in observations aloft (Fig. 8, right panel). Acetonitrile concentrations increased with altitude with a median (mean) of 72 (68) ppt(v) below $200 \mathrm{~m}, 89(81) \operatorname{ppt}(\mathrm{v})$ between 200 

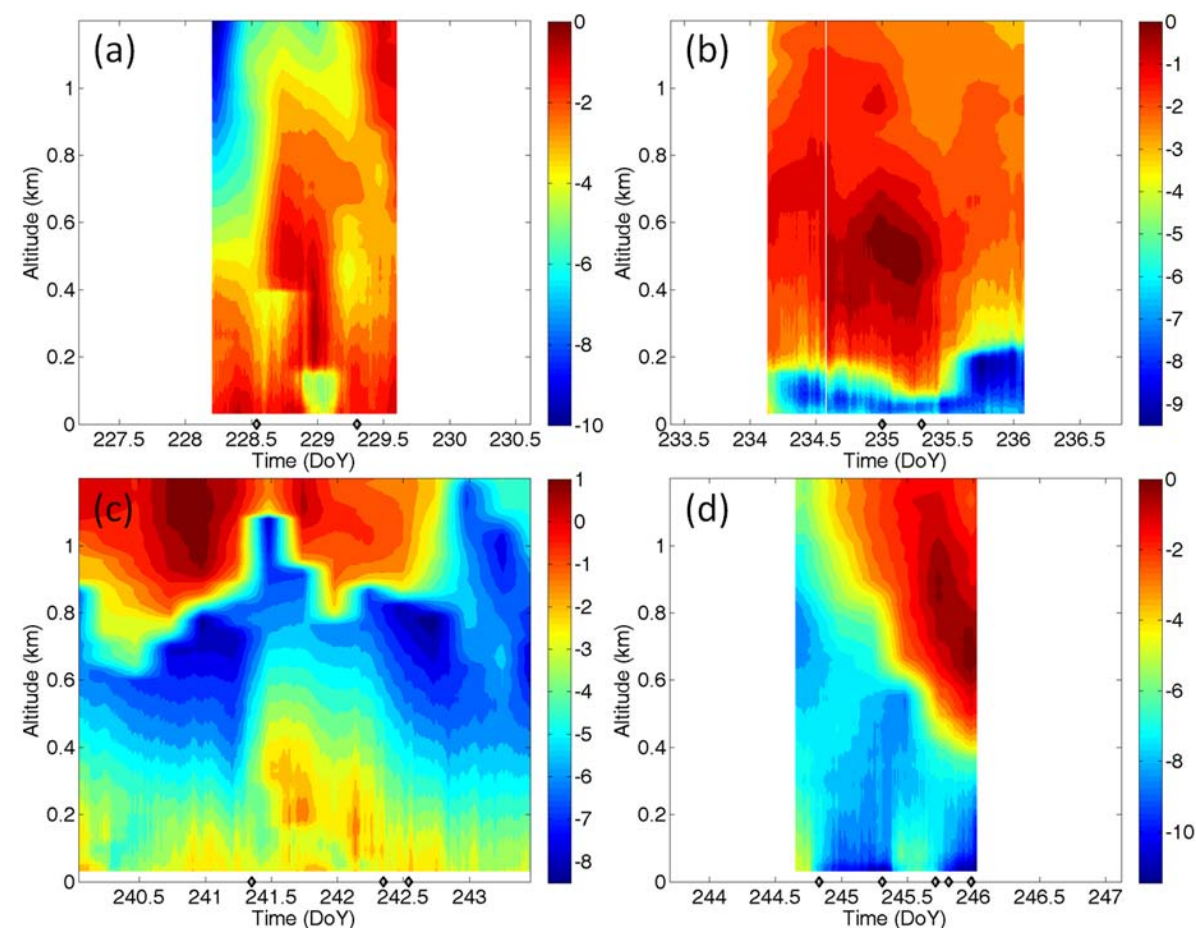

Fig. 6. Time-height cross-sections of temperature $\left[{ }^{\circ} \mathrm{C}\right]$ from a scanning microwave radiometer for the four periods: (a) period 1 , (b) period 2 , (c) period 3 and (d) period 4. In each panel start times for helicopter flights discussed in this paper are marked with diamonds on the time axis, and the time axis is adjusted to the same total length for all periods.
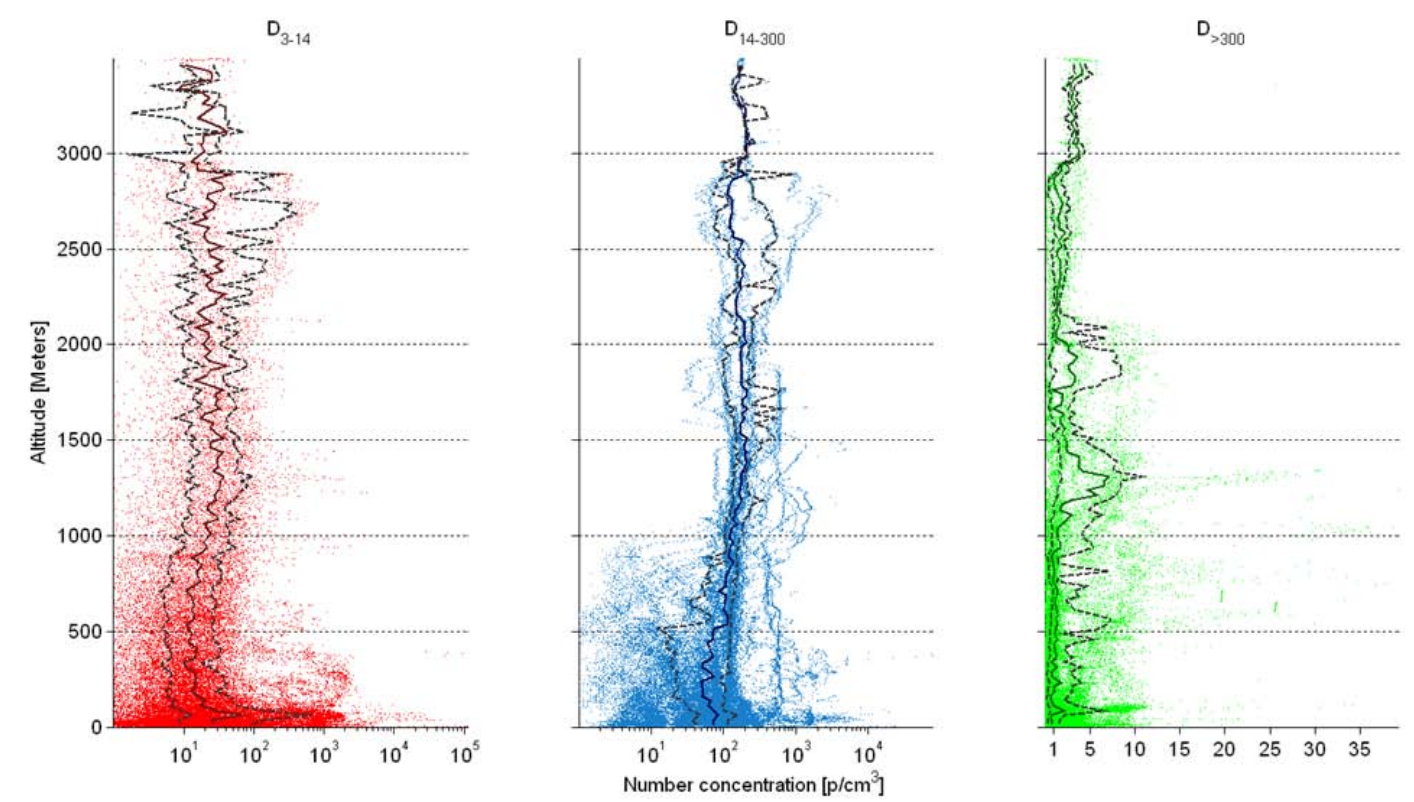

Fig. 7. Vertical aerosol number size concentration profiles taken across 38 flights carried out during the ice drift of the ASCOS 2008 expedition. The three sub-plots show concentrations of particles with diameters of 3-14 nm, 14-300 nm and over 300 nm respectively. Points are individual observations, the continuous line is the median of the measurements and the dashed lines are the upper and lower quartiles of the observations. 


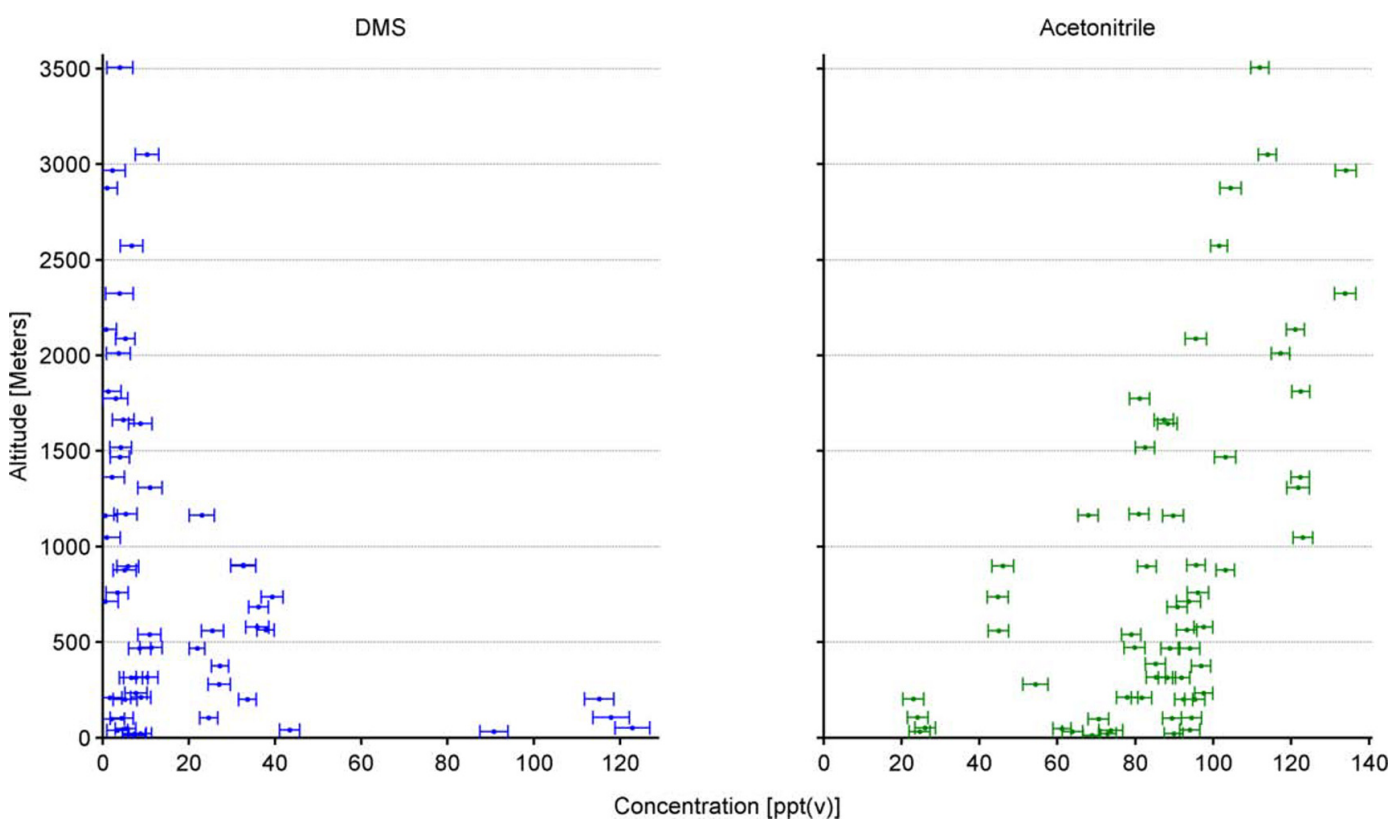

Fig. 8. Vertical dimethyl sulphide (DMS) and acetonitrile concentration profiles taken during eight flights carried out during the ice drift period of the ASCOS 2008 expedition. Blue and green points show DMS and acetonitrile concentrations respectively; error bars show the $95 \%$ confidence interval.

and $1000 \mathrm{~m}$ and $104(105) \mathrm{ppt}(\mathrm{v})$ above $1000 \mathrm{~m}$. Considering the long atmospheric lifetime of acetonitrile $(0.45 \mathrm{yr}$ according to Hamm and Warneck, 1990) and the large difference in concentrations observed between the layers closest to the surface and the free troposphere, the central Arctic Ocean appears to be a sink area for acetonitrile. The high acetonitrile concentrations in the free troposphere can be explained by biomass burning advected via long-range plume transport from lower latitudes (Warneke et al., 2009, 2010). The vertical trends of DMS were consistent with the pack ice model study by Lundén et al. (2010) in that the observations in Fig. 8 typically showed highest concentrations near the surface and decreased exponentially with height. Maxima of DMS (g) above the local boundary layer were present in about $3 \%$ of the modelled profiles. These maxima were found in association with frontal zones.

\subsection{Period 1: melt, 15-16 August (DoY 228-229)}

Helicopter flight period 1 is embedded in the first of the regimes discussed in Sect. 3.1. Thus, it commenced during the end of the melt season in a period characterised by large variability and high synoptic activity, with frequent fog and drizzle, along with persistent low-level stratiform cloud cover, generally located within the PBL (Figs. 3b, $5 \mathrm{c})$. The boundary layer depth was variable $(\sim 200-500 \mathrm{~m})$ and a pulse of warm air aloft associated with the passing of a weak high-pressure ridge between the two frontal systems marked the start and end of this period. The broadening of the $25-75$ percentile intervals (Fig. 5a, b) in the slightly sta- ble $300-800 \mathrm{~m}$ interval indicates this larger variability aloft, while below $200 \mathrm{~m}$ the median profiles show quasi-constant values with height. This is indicative of nearly well-mixed conditions. $\mathrm{RH}_{i}$ was high, near $100 \%$, up to $1 \mathrm{kma.g.l.,} \mathrm{and}$ $\Theta_{\mathrm{e}}$ had the largest values of the periods; large variability in $\mathrm{RH}_{i}$ aloft (>1 km, 20-100\%) is indicative of the formation, layering and dispersal of higher clouds. The profile of the median cloud fraction in Fig. 5c, evaluated from the cloud radar, shows near $100 \%$ cloudiness below $200-300 \mathrm{~m}$, but also considerable cloud fractions through much of the troposphere, with a minimum at $30 \%$ around $1-2 \mathrm{~km}$ but a substantial cloud fraction aloft. Of all periods discussed in this paper, this is the period with the largest vertical extent of cloud cover. During the helicopter flights, cloud base was visually observed at $180 \mathrm{~m}( \pm 20 \mathrm{~m})$ on 15 August (DoY 228) and at $125 \mathrm{~m}( \pm 25 \mathrm{~m})$ on 16 August (DoY 229). This was in good agreement with the ceilometer measurements, according to which the cloud base was at $206 \mathrm{~m}$ and $118 \mathrm{~m}$ during the flights on 15 August (DoY 228) and 16 August (DoY $229)$ respectively. The cloud top of the lowermost cloud layer was reached on 15 August (13:16 UTC) at $270 \mathrm{~m}$, observed visually and confirmed by RH decreasing from a constant value of $100 \%$ in cloud to $97.7 \%$ above cloud top.

Helicopter aerosol profiles from the melt period (Fig. 9a) show raised concentrations of $D_{>300}$ particles within the lowermost 100 ma.g.l. On 15 (16) August, concentrations below $100 \mathrm{~m}$ were ca. $7 \mathrm{~cm}^{-3}\left(4 \mathrm{~cm}^{-3}\right)$, declining to ca. $2 \mathrm{~cm}^{-3}\left(1 \mathrm{~cm}^{-3}\right)$ within the lowermost cloud layer. The number size distribution of particles obtained using the TDMPS on board Oden shows a strong bimodal distribution 
(Fig. 10a), with the Aitken- and accumulation-mode particles separated by a Hoppel minimum (Hoppel et al., 1994).

The observed bimodal number size distribution on board ship is characteristic of cloud-processed marine air masses (Hoppel et al., 1994) and suggests an aerosol source from the marginal ice zone (MIZ) and/or open water south thereof. This is coherent with both the air mass trajectory cluster, which shows air predominantly from the Greenland Sea reaching the $100 \mathrm{~m}$ level at the position of Oden during this period (Fig. 4a), as well as with the short air mass transit time over ice (1.2 days). Positive matrix factorization (PMF) of the mass spectrum obtained using an aerosol mass spectrometer (AMS) also supports the marine air mass hypothesis, with a high marine biogenic factor during this period (Chang et al., 2011). The increased concentrations of $D_{>300}$ particles within the near-surface layer (Fig. 9a) are then likely to have been a result of the following process, described in a number of previous studies (Leck and Bigg, 2005b, 2007): precursor gases such as DMS oxidation products, transported within the boundary layer from the MIZ, could have condensed on smaller, Aitken-mode particles present over the pack ice (Kerminen and Leck, 2001; Heintzenberg et al., 2006), growing them to $\mathrm{CCN}$ sizes and allowing them to be activated into cloud droplets. Activated particles could then be grown via in-cloud aqueous-phase oxidation of gases such as sulphur dioxide $\left(\mathrm{SO}_{2}\right)$, resulting in release of larger particles following droplet evaporation (Hoppel et al., 1994).

A further mechanism which may have contributed to the higher near-surface $D_{>300}$ concentrations is direct primary emissions. This would involve the release of accumulationmode particles from the MIZ or open leads via bubble bursting. It is important to note that the aerosol source flux over the open sea has been found to be an order of magnitude stronger than that from open leads, based on measurements using the eddy-covariance flux method (Nilsson et al., 2001). However, based on statistics of modal aerosol number concentrations of data from all four Oden based expeditions, Heintzenberg and Leck (2012) discussed the selective "filter" effects of scavenging of aerosol particles in fog and low clouds in air entering the pack ice from the MIZ. This sink region in the MIZ, within < 2 DOI, for particles in the submicron size range (Nilsson and Leck, 2002) was confirmed. This suggests that in conditions in which the air has been in very recent contact with the MIZ/open water, primary particles are likely to contribute to the aerosol number and CCN population observed over the pack ice. These conditions with a relatively large aerosol flux over the MIZ/open water relative to open leads also further explains why upstream boundary layer transport from the MIZ results in raised concentrations of $D_{>300}$ particles as seen in Fig. 9a, representing air with about one day since last contact with open sea.

Decreases in the number concentrations of both $D_{14-300}$ and $D_{>300}$ particles with altitude can be seen, starting at a height of approximately 140 ma.g.l. on 15 August and approximately $100 \mathrm{ma.g.l}$. on 16 August (Fig. 9a), and coin- cided quite well with the visually identified cloud base. The decreases can be explained by cloud processing of $D_{14-300}$ and $D_{>300}$ particles within the cloud layer. First, particle scavenging (and the possible subsequent wet deposition) leads to a net decrease in the number concentration. Second, as particle activation takes place, droplets may grow to sizes too large to be sampled by the helicopter inlet $(9.5 \mu \mathrm{m}$ cut-off). As a result, particles within droplets large enough to be lost via settling or impaction in the inlet tubing will not be detected. In the case of $D_{14-300}$ particles, the measured number concentrations include both Aitken-mode and smaller accumulation-mode particles. Generally the Aitkenmode particles are not activated as efficiently in-cloud, therefore the measured number concentrations of Aitken-mode particles should be affected to a much smaller extent by the cloud layer. Consequently, the relative decrease in the number of $D_{14-300}$ particles (from ca. $200 \mathrm{~cm}^{-3}$ to ca. $130 \mathrm{~cm}^{-3}$ ) is lower than that of the $D_{>300}$ size range (from ca. $7 \mathrm{~cm}^{-3}$ to ca. $2 \mathrm{~cm}^{-3}$ ), which is made up entirely of accumulationmode or larger particles.

Above the cloud, during the flight of 15 August, $D_{>300}$ particles increased in number. This could be due to evaporation of droplets and release of the cloud-processed particles above the cloud top. However, the number of $D_{14-300}$ particles did not increase. A possible reason is coalescence of droplets as a result of turbulent processes, leading to a monomodal cloud droplet distribution and an increase in the particulate matter contained within the droplets. Upon droplet evaporation, the particles released would then be predominantly larger accumulation-mode particles.

\subsection{Period 2: cold spell, 21-23 August (DoY 234-236)}

Helicopter flight period 2 is embedded in the second regime discussed in Sect. 3.1, and the time-height cross-section of temperature (Fig. 6b) reveals a much shallower PBL than that of the previous period; it is quite shallow initially, only 100$150 \mathrm{~m}$, but deepens somewhat around DoY 235.5 as a low cloud layer appears and deepens from 100 to 250 ma.g.l. (Sedlar et al., 2011). A weak pulse of warm air passes aloft, but on the whole, the vertical structure remains reasonably consistent throughout the period. While the very lowest layer, below $100 \mathrm{~m}$, is well-mixed (quasi-constant $\Theta_{\mathrm{e}}$, Fig. 5a), the temperature profile shows the colder low-level air and a stably stratified layer - an inversion - up to $\sim 250$ ma.g.l.; the percentile interval is large, indicating some variability in this layer, while conditions aloft have very little variation and the static stability is more typical of the free troposphere.

Interestingly, $\mathrm{RH}_{i}$ remained high and quasi-constant through a much deeper layer than the well-mixed thermal layer, up to $200 \mathrm{~m}$ a.g.l. and well into the inversion (Fig. 5b). This implies that the absolute moisture must have increased with height through a deep layer. Also note that $\mathrm{RH}_{i}$ was often $>100 \%$ and that clouds, when present, contained supercooled liquid droplets. The cloud fraction (Fig. 5c) was high 

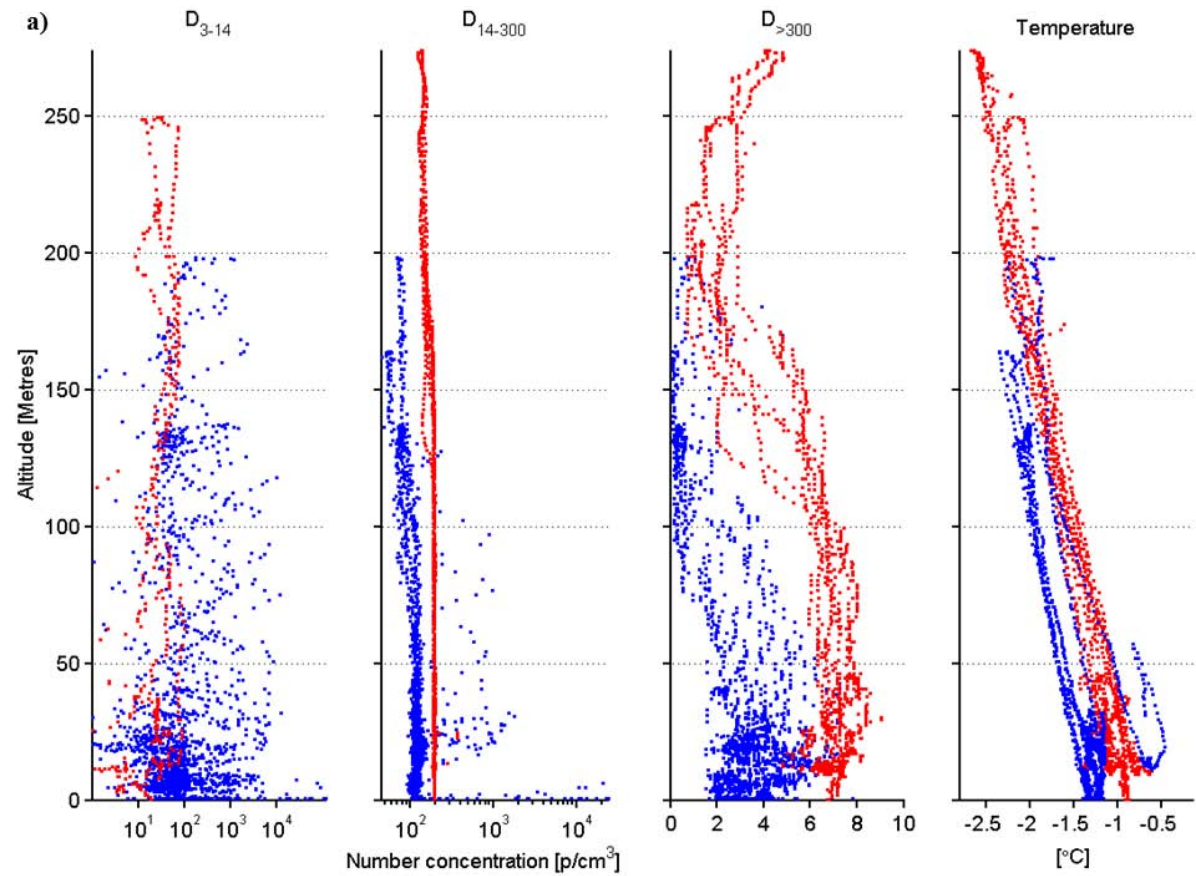

Fig. 9a. Vertical profiles of aerosol particle number concentration and temperature during ASCOS 2008 expedition helicopter flights, Period 1: 13:04-13:32 UTC, 15 August (DoY 228) 2008 (red); 07:10-08:00 UTC, 16 August (DoY 229) 2008 (blue).
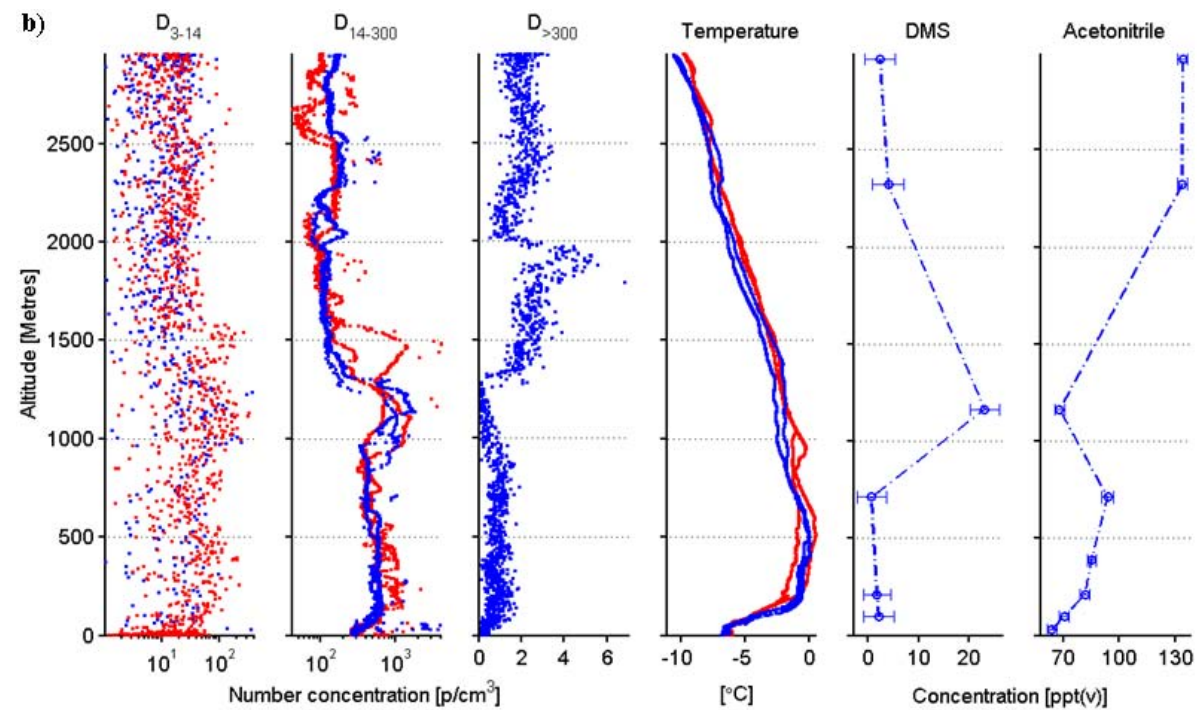

Fig. 9b. Vertical profiles of aerosol particle number concentration, temperature, and dimethyl sulphide (DMS) and acetonitrile concentrations (error bars give the $95 \%$ confidence interval) during ASCOS 2008 expedition helicopter flights, Period 2: 23:17-23:57 UTC, 21 August (DoY 234) 2008 (red); 07:26-08:03 UTC, 22 August (DoY 235) 2008 (blue). 
near the surface but decreased rapidly with altitude, except for the semi-transparent cirrus layer 6-7 kma.g.l. discussed earlier (Sect. 3.1). Most of the clouds were in the form of fog or very low stratus with the exception of the upper cirrus layer.

Profiles from both flights conducted during the cold spell show strong increases in the $D_{14-300}$ mode concentrations at ca. 1000-1500 ma.g.l., with raised DMS concentrations and a local acetonitrile minimum measured during the flight on 22 August (Fig. 9b). A further characteristic feature is a plume of $D_{>} 300$ particles between 1300 and 2000 ma.g.l. during the flight on 22 August (no profile is available in this size range for the 21 August flight due to instrumental issues). Meanwhile, the particle number size distribution as measured by the TDMPS instrument on board ship shows a single Aitken mode in aerosol number concentration (Fig. 10b). The single Aitken- modal distribution suggests an aerosol population sourced in the free troposphere (Covert et al., 1996; Heintzenberg et al., 2004). This is also supported by analysis of lead-210 content from on board Oden; lead-210 is a tracer for land contact that has been employed successfully in previous studies (Paatero et al., 2010; Chang et al., 2011). The measured concentrations of ca. $35 \mu \mathrm{Bqm}^{-3}$ are relatively low - this is a value typical of contact with nonbare (e.g. ice-sheet covered) land. The air trajectory showing a subsiding pathway from the free troposphere via across Greenland to the surface also points to an air mass of free tropospheric origin. Finally, the low marine biogenic factor (Chang et al., 2011) also suggests an air mass arriving at the surface without recent contact with the marine-influenced PBL.

As regards the aerosol plumes observed aloft, the back trajectories suggest that the air was advected from the Canadian Arctic Archipelago, and had a downwards-sloping pathway as it moved towards the high Arctic as shown in Figs. $4 \mathrm{~b}$ and 11.

\subsection{Period 3: preconditioning, 27-30 August (DOY 240-243)}

Period 3 is the longest time period discussed in this paper and the helicopter flights analysed in detail below occurred near the end of this regime. Period 3 was characterized by a stratocumulus layer with intermittent periods of multiple cloud layers below $1500 \mathrm{ma.g} .1$. (Fig. 3b). The capping inversion at the top of the clouds is visible in Fig. $6 \mathrm{c}$ as it varies in height from approximately $600 \mathrm{~m}$ up to $>1200 \mathrm{ma}$ a.g.l. (the upper limit of this instrument) in response to synoptic variability. Another interesting feature seen is a secondary inversion that forms around 200 ma.g.l. just before DoY 241.5, coinciding with a vertical rise of the cloud layer by $\sim 300 \mathrm{~m}$. A low-level jet with a local wind maximum develops near 200 ma.g.l., causing a decoupling of the cloud-driven turbulent mixed layer (400-800 ma.g.1.) and shear-driven PBL from the surface to $\sim 200$ ma.g.l. Eventually a brief sec- ondary cloud layer develops in response to the mechanical mixing of the PBL and moistening from evaporation and/or sublimation of precipitation from the original, but now upper, cloud layer. This case indicates the delicate balance between mesoscale forcing and cloud-driven mixing and diabatic processes occurring in the lower Arctic troposphere where the mixing generated by surface- and cloud-induced turbulence together become no longer sufficient to keep the whole layer mixed. Statistical profiles in Fig. 5a and b also reflect this structure. Below $100 \mathrm{ma.g} .1$, the variability in temperature is small; it then increases with altitude to about $800 \mathrm{~m}$ and then decreases again up through the very stable interface to the free troposphere. The main cause for the increased variability in the 200-800 $\mathrm{m}$ layer were the changes in altitude of the original single cloud layer and the formation of the secondary inversion - which becomes further enhanced by the formation of a low-level cloud layer near 200 ma.g.l. The RH supports this analysis; $\mathrm{RH}_{i}$ increases with height from the surface to $\sim 200 \mathrm{~m}$, then decreases in a layer $\sim 200-400 \mathrm{~m}$ but increases again from $400 \mathrm{~m}$ to almost $1 \mathrm{~km}$ and then falls rapidly to $\sim 40 \%$ in the free troposphere (Fig. $5 \mathrm{~b}$ ); thus also here the moist layer is deeper than the mixed layer. In the lower moist layer, $\mathrm{RH}_{i}$ mostly remains at or below $100 \%$; in the upper layer however, $\mathrm{RH}_{i}$ is almost always $>100 \%$.

Tjernström et al. (2012) offers the following explanation for this vertical structure. Turbulent mixing by surface friction is able to mix the lowest $100-200 \mathrm{~m}$ at most, while the cloud-generated turbulence (from cloud-top cooling by longwave radiation) mixed a much deeper layer, from the cloud top downward. When one or the other, or both, was strong and/or the distance between the surface and the cloud base was sufficiently small, the two processes combined and caused a single deep, well-mixed layer from the surface to cloud top. When this did not happen, such as around DoY 241.5 , the layers separated and the cloud layer was essentially decoupled from any processes at the surface, such as turbulent surface fluxes. Turbulent surface fluxes were thus limited in vertical extent to only about $200 \mathrm{~m}$ a.g.l. The radarderived cloud fraction for period 3 (Fig. 5c) remains close to $100 \%$ below 800 ma.g.l. Below some hundreds of metres this is probably an overestimate, due to the fact that the radar picks up the signal from the quasi-constant frozen precipitation; unfortunately this is impossible to separate from the actual cloud. The emergence of an independent cloud layer below $200 \mathrm{~m}$ a.g.1., as observed by the cloud ceilometer, also contributed to the high cloud fraction. Ceilometer measurements of clouds base indicate that patchy fog and low clouds were common during this period. At about $800 \mathrm{~m}$, however, the cloud fraction drops dramatically to very low values through the rest of the free troposphere, consistent with the low RH.

The helicopter aerosol concentration profile obtained during the flight on 28 August shows a well-defined plume of $D_{>300}$ particles with raised concentrations between approximately 400 and $700 \mathrm{~m}$ (Fig. 9c), coinciding with an increase 

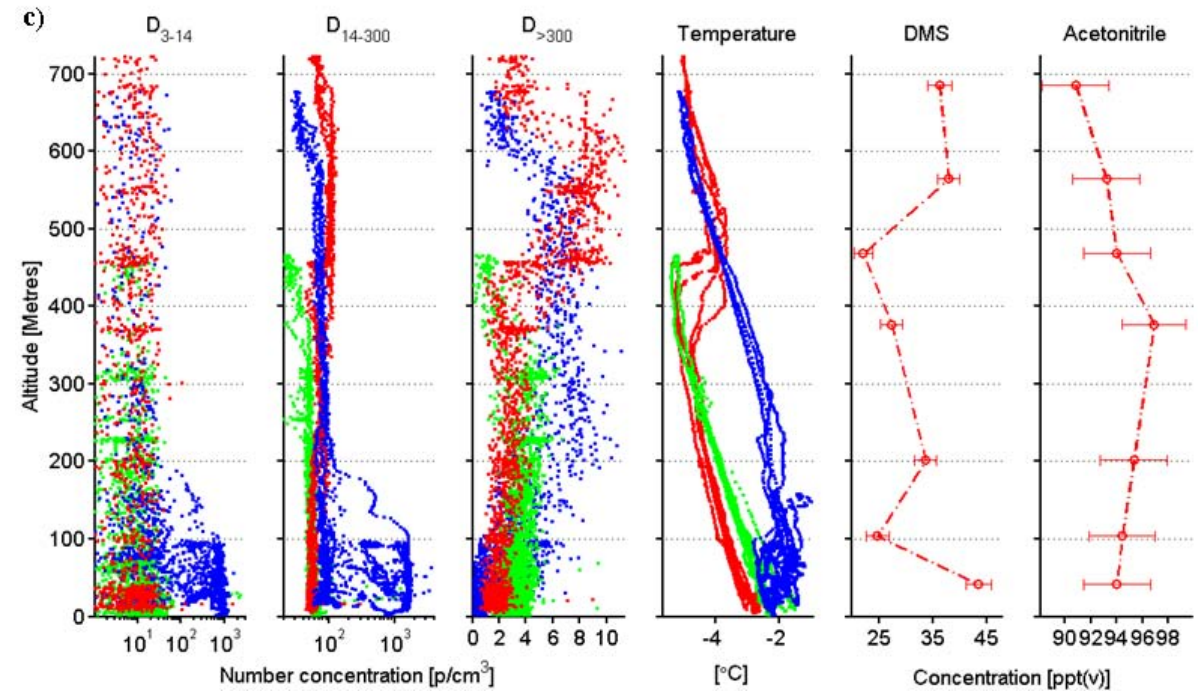

Fig. 9c. Vertical profiles of aerosol particle number concentration, temperature, and dimethyl sulphide (DMS) and acetonitrile concentrations (error bars give the $95 \%$ confidence interval) during ASCOS 2008 expedition helicopter flights, Period 3: 08:40-09:16 UTC, 28 August (DoY 241) 2008 (red); 08:30-09:16 UTC, 29 August (DoY 242) 2008 (blue); 13:07-14:07 UTC, 29 August (DoY 242) 2008 (green).
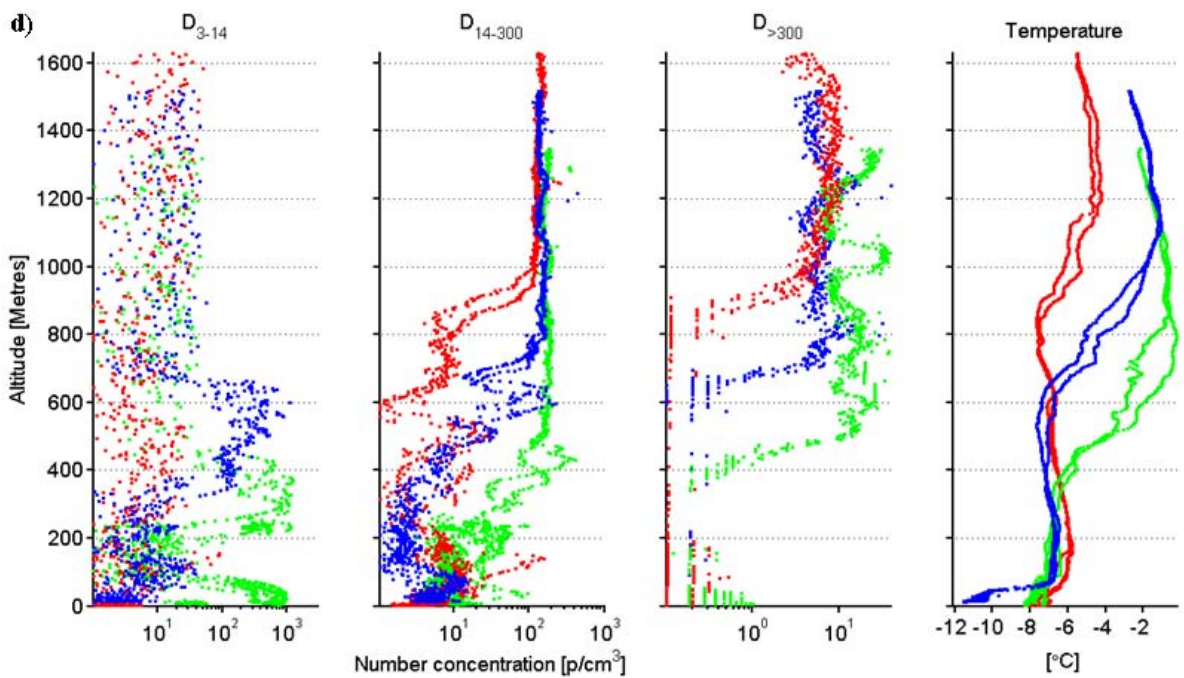

Fig. 9d. Vertical profiles of aerosol particle number concentration and temperature during ASCOS 2008 expedition helicopter flights, Period 4: 19:53-20:13 UTC, 31 August (DoY 244) 2008 (red); 07:32-07:55 UTC, 1 September (DoY 245) 2008 (blue); 17:19-17:40 UTC, 1 September (DoY 245) 2008 (green). 
in cloud base height across the same vertical depth. The lower boundary of the plume is in good agreement with the inversion base, as inferred from the in-flight temperature profile (Fig. 9c). Furthermore, vertical profiles of the Richardson number indicate sustained turbulence between ca. 400 and $700 \mathrm{~m}$ (I. Brooks, personal communication, 2011), suggesting the confined nature of the plume is indeed a result of vertical mixing via cloud-driven buoyancy circulations penetrating a few hundred metres below cloud base. Chemical tracer analysis shows a local DMS maximum of $37 \mathrm{ppt}(\mathrm{v})$ at 600 ma.g.l. (Fig. 9c) indicating contact with marine areas, pointing to the possible involvement of DMS oxidation products in the growth of the accumulation particles; DMS also shows a local maxima just above the surface which may have contributed to the development of a lower, secondary cloud layer and decoupling observed shortly after this flight.

The following flight on 29 August at ca. 09:00 UTC shows a broader layer, from ca. $100 \mathrm{~m}$ to $600 \mathrm{~m}$ with raised $D_{>300}$ particle concentrations (Fig. 9c). A single cloud layer with a base descending from $700 \mathrm{~m}$ to approximately $550 \mathrm{~m}$ occurred just prior to the flight in response to the low-level jet with decreasing height during the same time. A breakdown of the decoupling between the turbulent sub-cloud layer and the turbulent surface layer, resulting in a deepening of the mixed layer throughout the 29th, was visible in the Richardson number profile (I. Brooks, personal communication, 2011), explaining the widening of the $D_{>300}$ particle plume relative to the distribution measured during the previous flight. A thin layer of air with limited mixing within the lowest ca. $100 \mathrm{~m}$, as well as the weak temperature inversion visible in the inflight profile (Fig. 9c) may have prevented mixing down of the particles all the way to the surface. Consequently, it could be hypothesized that the cloud is partially responsible for the decrease of the height of the plume's upper boundary due to activation and more rapid deposition of particles at the upper edge of the plume.

A further feature in the vertical aerosol profile on $29 \mathrm{Au}$ gust at ca. 09:00 UTC are very high concentrations, on the order of $1000-2000 \mathrm{~cm}^{-3}$, of both $D_{3-14}$ and $D_{14-300}$ particles below 100 ma.g.l. At this time, an increase in particle concentrations within the size range of approx. 3-30 nm was detected by the TDMPS on board Oden (Fig. 10c). See period 4 for possible explanations.

A third flight conducted $4.5 \mathrm{~h}$ later shows that the layer of air with raised $D_{>300}$ particle concentrations reached the surface (Fig. 9c), which can be explained by the deepening of the mixed layer down to ground level at this time, the subsidence of cold air from aloft and an almost complete disappearance of the temperature inversion. An increase in accumulation-mode particle concentrations is also detected by the TDMPS on board Oden (Fig. 10c), confirming the helicopter measurements. The upper extent of the plume of $D_{>300}$ particles has decreased in altitude relative to the previous flight, which may be due to a further lowering of the cloud base before the flight to ca. $430 \mathrm{~m}$. For a further in- depth case-based analysis of the interactions between the boundary layer, surface fluxes, aerosol concentrations and stratiform clouds during this period, the reader is referred to Shupe et al. (2013).

\subsection{Period 4: freeze-up, 31 August-2 September (DoY 244-246)}

The final period, occurring at the end of the ice drift, is two days long and structurally bears some resemblance to period 2. It was dominated by subsidence and dissipation of the stratocumulus layer, previously present for almost a week (see above). Figure 6d shows the subsiding warm air aloft, with a main capping inversion descending from $\sim 800 \mathrm{~m}$ essentially down to the surface. Cloud fraction averaged over this period was low and only reached near $95 \%$ just above the surface (Fig. 5c). Two pulses of relatively warmer temperatures (Fig. 3a) were associated with patches of clouds or fog, primarily around midday on DoY 245.

Similar to in period 2, there was a dramatic temperature drop at the surface as a consequence of the dissipation of the surface-warming clouds (Sedlar et al., 2011); near-surface temperatures dropped to below $-10^{\circ} \mathrm{C}$, (Fig. 3a). As a consequence, the PBL was stably stratified (Fig. 5a). Compared to period 2, which was also stably stratified except for the lowest $50-100 \mathrm{~m}$, period 4 was continuously stably stratified all the way down to the surface. However, the stability in the capping inversion of period 2 was much stronger than in period 4; the layer between 100 and 300-400 ma.g.l. during period 4 has a structure reminiscent of a residual layer, clearly showing the remnants of mixing by the previous stratocumulus layer. Thus the temperature profile in Fig. 5a shows a variable but stable layer between the surface and $\sim 150 \mathrm{~m}$; above this the stability is weaker in the layer up to $\sim 400 \mathrm{~m}$ followed by the capping inversion, which is up to a kilometer in height. The enhanced variability is indicated by the broadening of the inter-quartile range of equivalent potential temperature (Fig. 5a).

$\mathrm{RH}_{i}$ was $>100 \%$ in a layer from the surface up to $\sim 200 \mathrm{~m}$, (Fig. 5b); however, in contrast to the previous periods, where the $\mathrm{RH}_{i}$ and cloud fraction profiles were consistent, the cloud fraction was high at the surface but dropped off with altitude - to $80 \%$ at $200 \mathrm{~m}$, and below $40 \%$ above $300 \mathrm{~m}$ where $\mathrm{RH}_{i}$ was still $\sim 100 \%$. Clouds were entirely absent above $800 \mathrm{~m}$. This period coincided with an episode of very low concentrations of cloud condensation nuclei, described in detail in Mauritsen et al. (2011), where they identified a tenuous Arctic cloud regime and subsequent surface forcing strongly linked to the absence of CCN despite sufficiently large $\mathrm{RH}$ present.

Based on the helicopter profiles, concentrations of $D_{>300}$ aerosol particles were very low within the lowermost few hundred metres (Fig. 9d, e), with concentrations usually below $0.5 \mathrm{~cm}^{-3}$, as compared to ca. $4-7 \mathrm{~cm}^{-3}$ during period 1 , ca. $1 \mathrm{~cm}^{-3}$ during period 2 and ca. $2-10 \mathrm{~cm}^{-3}$ during 

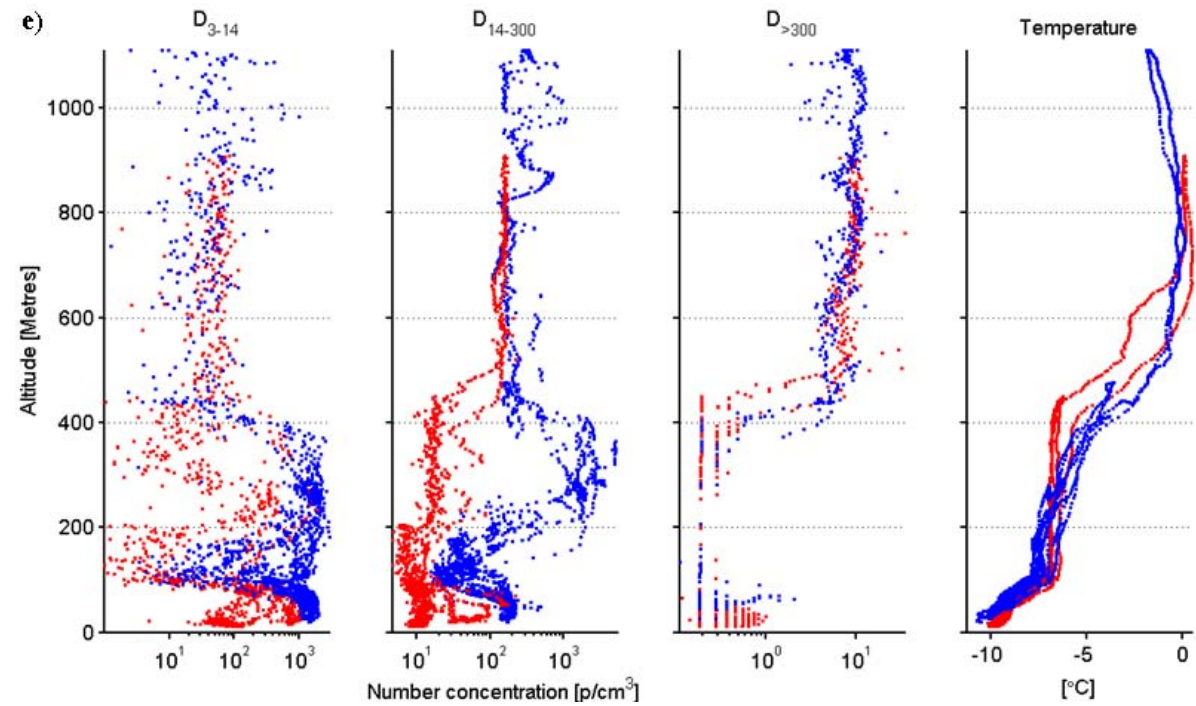

Fig. 9e. Vertical profiles of aerosol particle number concentration and temperature during ASCOS 2008 expedition helicopter flights, Period 4: 19:39-20:10 UTC, 1 September (DoY 245) 2008 (red); 23:40-00:17 UTC, 1 September (DoY 245), 2008 (blue).
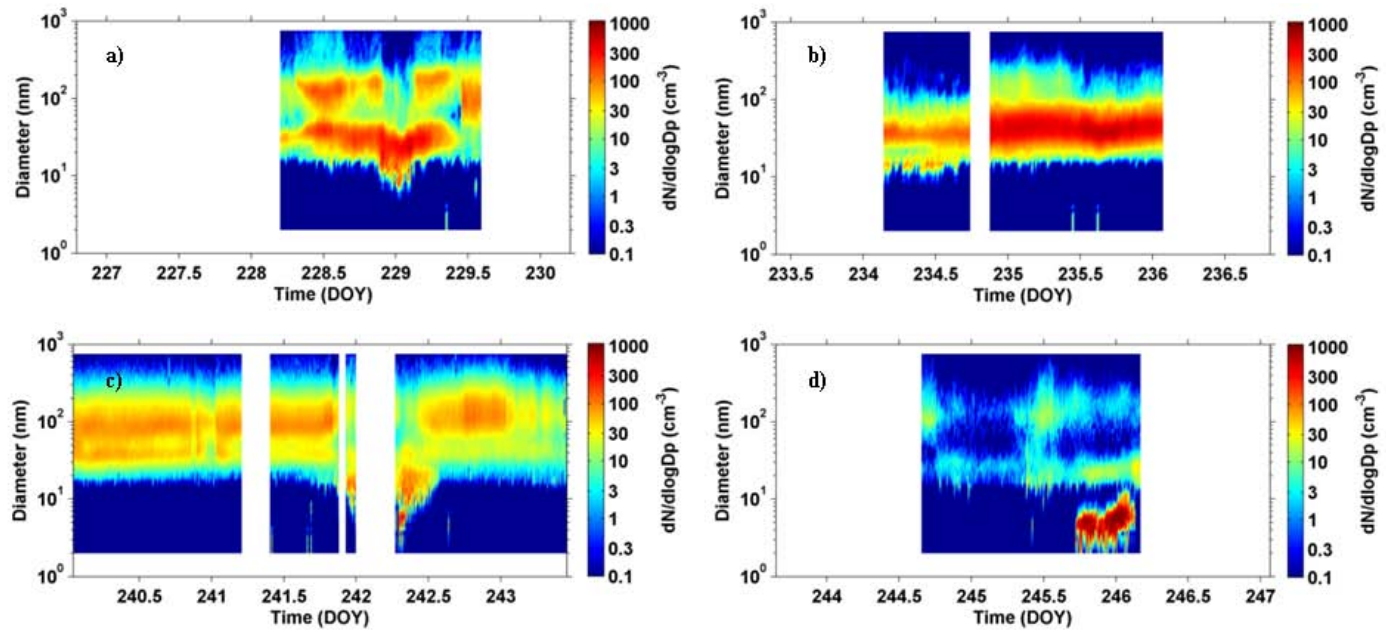

Fig. 10. Particle number size distribution measured by the Twin Differential Mobility Particle Sizer (TDMPS) instrument on board Oden icebreaker during the ASCOS 2008 expedition: (a) period 1, (b) period 2, (c) period 3 and (d) period 4. Periods shown as blank indicate where measurements were flagged as contaminated. 
period 3. Oden TDMPS measurements show a strong decrease in accumulation-mode particle concentration starting in the second half of 31 August (Fig. 10d), confirming the flight observations. The low aerosol particle concentrations result in an almost complete disappearance of clouds which was observed from ca. 20:00 UTC on 31 August. This is the atmospheric state described by Mauritsen et al. (2011) as a CCN-limited regime, whereby the lack of CCN particles hinders cloud droplet formation and resultant feedback on the surface energy budget (Sedlar et al., 2011).

At higher altitudes, the concentration of both $D_{14-300}$ and $D_{>300}$ aerosol particles increased over several hundred metres. The flight on 31 August (Fig. 9d) shows the lower border of the plume at approximately 850 ma.g.1.; it decreases over time to ca. $550 \mathrm{~m}$ and ca. $400 \mathrm{~m}$ during subsequent flights (Fig. 9d), closely following the decrease in the inversion base height (Fig. 6d). The plume remains above approximately $400 \mathrm{~m}$ throughout the two final flights on 1 September (Fig. 9e).

Ultrafine $D_{3-14}$ particles were first measured with concentrations of $600 \mathrm{~cm}^{-3}$ in a layer at $400 \mathrm{ma}$ a.g.l. on the evening of the 31st (Fig. 9d). This layer persisted throughout the flights on the 1st (Fig. 9d, e), and was closely situated below the inversion heights mentioned above. The layer broadens to about $300 \mathrm{~m}$ thickness, and maximum concentrations of $D_{3-14}$ particles increase up to $2000 \mathrm{~cm}^{-3}$ during daytime on the 1st. High near-surface concentrations of $D_{3-14}$ particles were detected during the second flight, at 17:20 UTC, on 1 September (Fig. 9d), with an increase in concentrations to over $1000 \mathrm{~cm}^{-3}$. At this time the TDMPS measurements on board Oden show a simultaneous increase in ultrafine and Aitken-mode particles (Fig. 10d), also bearing witness to a new particle formation (NPF) event. A review of similar kinds of NPF events observed over the high Arctic pack ice has been presented in a recent paper by Karl et al. (2012).

As shown by Karl et al. (2012), the rapid appearance of the sub-10 nm particles cannot be explained as a result of the growth of the freshly nucleated stable clusters of 1-2 nm diameter by a condensable organic vapour essentially because the Kelvin effect imposes a giant barrier for these clusters' initial growth (Zhang and Wexler, 2002; Karl et al., 2011). However, occasional nucleation of DMS-derived $\mathrm{H}_{2} \mathrm{SO}_{4}$ followed by subsequent growth involving organic vapours is also supported by Karl et al. (2012).

In addition, it was shown that the availability of condensable vapours is limited in the PBL over the inner Arctic, and that the concentration of DMS, a precursor to $\mathrm{H}_{2} \mathrm{SO}_{4}$, is often not sufficient to sustain growth into the super $10 \mathrm{~nm}$ diameter size range (Karl et al., 2013), leaving the observed coappearance of particles in the $20-50 \mathrm{~nm}$ diameter size range coinciding with nucleation unexplained in many cases. Also during this NPF event during period 4, the concentrations of precursor gases measured by the PTR-TOF on board Oden were very low (DMS concentrations were below the detection limit of $4 \operatorname{ppt}(\mathrm{v})(30 \mathrm{~min}$ integration)), preventing the
NOAA HYSPLIT MODEL

Backward trajectories ending at 0800 UTC 22 Aug 08 GDAS Meteorological Data

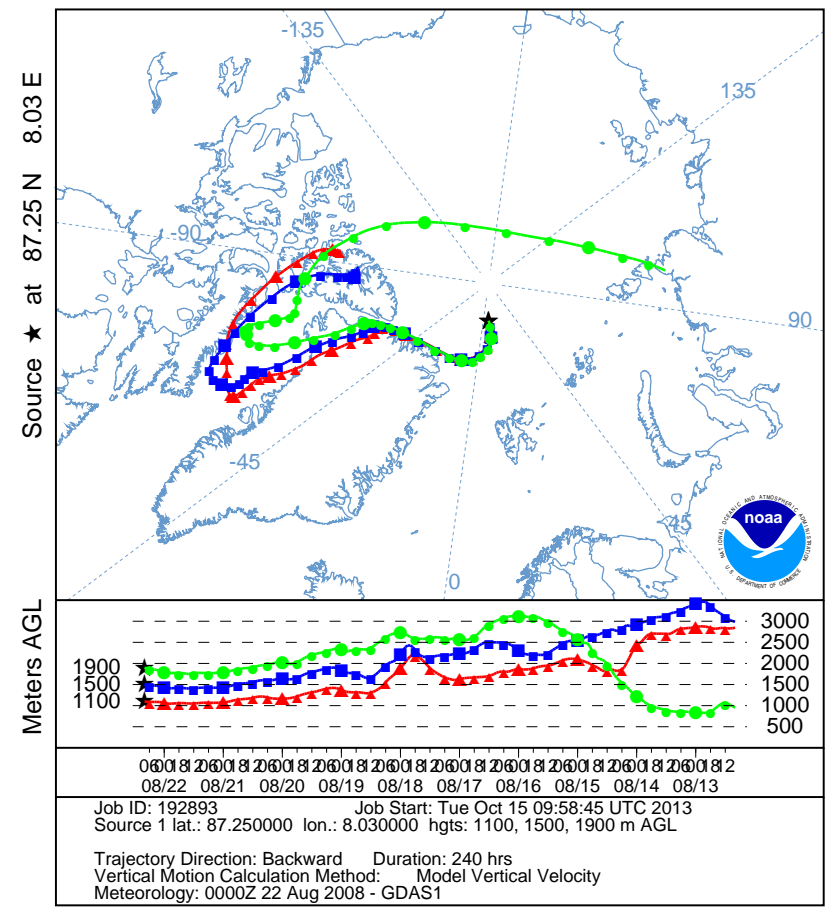

Fig. 11. 10-day backward air mass trajectory ending at 08:00 UTC, 22 August 2008 at $87.25^{\circ} \mathrm{N} 8.03^{\circ} \mathrm{E}$, calculated for $1100 \mathrm{~m}$ (red), $1500 \mathrm{~m}$ (blue) and $1900 \mathrm{~m}$ (green) receptor point altitude. Source: calculated using the HYSPLIT model http://www.arl.noaa.gov/ HYSPLIT.php.

Kelvin barrier from being overcome, and thus excluding further possible growth of nanometre-sized clusters.

Again the simultaneous increases in concentration occurring in both the $D_{3-14}$ and $D_{14-300}$ size ranges suggest that a different mechanism may have been involved. In an attempt to explain the characteristics of the new particle formation events in the high Arctic, a hypothesis has been put forward linking the NPF events to evaporation of low-level cloud or fog droplets brought about by mixing of the droplets with dry air at the top and edges of a cloud/fog (Leck and Bigg, 2010; Karl et al., 2013), whereby particle breakup could take place during evaporation.The fragmentation of particles released from the evaporating cloud droplets could result in release of both ultrafine particles and Aitken-mode particles (Leck and Bigg, 2010). Based on the visibility and ceilometer measurements located on board Oden, rapid evaporation of low cloud/fog droplets was observed approximately 36 min before the start of the new particle formation event seen by the TDMPS. The combination of particle release from droplets together with classical nucleation and growth involving $\mathrm{H}_{2} \mathrm{SO}_{4}$ and organic vapours is thus suggested to have been responsible for the NPF event. Indeed, a modelling study carried out by Karl et al. (2013) shows good agreement 

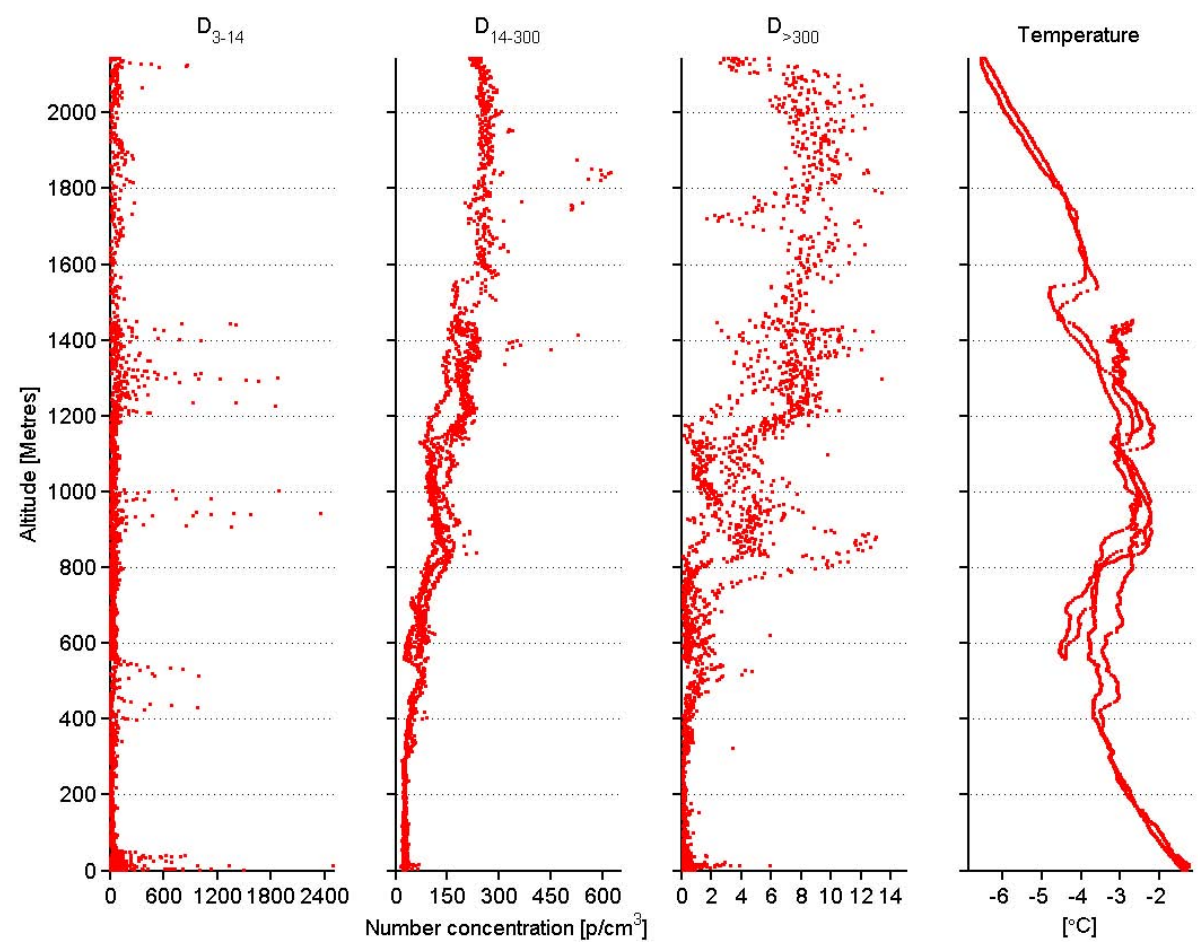

Fig. 12. Vertical profile of aerosol particle number concentration and temperature during ASCOS 2008 expedition helicopter flight, 07:5708:41 UTC, 20 August (DoY 233) 2008.

with observed number concentrations, when both nucleation and growth of condensable vapours as well as emissions of marine nanogels are simulated. Most likely, the relative contribution of nucleation and growth by $\mathrm{H}_{2} \mathrm{SO}_{4}$ and condensable organic vapours to the observed increase in concentrations in the sub-10 $\mathrm{nm}$ size range became greater several hours later, during the early hours of 2 September, when the origin of the incoming air mass shifted to the Beaufort Sea. The shift in the direction of air mass flow was accompanied by a decrease in the DOI to 3.5 at 06:00 UTC on 2 September from the average DOI of 8.2 during period 4 . Due to the shift to a lower DOI, the precursor gases reaching Oden increased to detectable concentrations around 00:53 UTC on 2 September, with DMS concentrations between 5 and $15 \mathrm{ppt}(\mathrm{v})$ (data not shown), thus further providing material for early growth of the new particles. The third flight on 1 September (Fig. 9e) also shows high near-surface concentrations of $D_{3-14}$ particles, as well as an increase in $D_{14-300}$ near-surface concentrations with respect to the previous flight. Several profiles during 1 September show the highest ratio of $D_{3-14}$ particles to $D_{14-300}$ particles to be situated in the lower part of the layer at ca. 300-400 ma.g.1., just above the cloud top, measured by the MMCR instrument at $253 \mathrm{~m}$, possibly indicating a particle source from evaporation of cloud droplets. The fourth and final flight on 1 September (Fig. 9e) shows a further increase in $D_{3-14}$ concentrations up to $3000 \mathrm{~cm}^{-3}$. A strong increase in $D_{14-300}$ particle concentrations is vis- ible between 200 and $400 \mathrm{~m}$, and, interestingly, the feature seems to be entirely decoupled from the lowermost $200 \mathrm{~m}$. Visually, a thin (approximately $50 \mathrm{~m}$ ) haze layer centered at $125 \mathrm{~m}$ altitude was observed during the last flights; it effectively scavenged ultrafine particles by Brownian diffusion, with concentrations at $125 \mathrm{~m}$ altitude reaching as low as $<100 \mathrm{~cm}^{-3}$ before midnight.

\section{Case study: free troposphere plumes and long-range transport}

In a number of cases, the aerosol profiles contained distinct plumes within the free troposphere. While the summertime Arctic atmosphere is believed to be very clean in the PBL (Bigg et al., 1996; Leck et al., 1996), the plumes in air aloft, above the PBL, are caused by the occasional transport of polluted air from lower latitudes. One possible source of intrusions of polluted air within the free troposphere may be biomass burning. The following case study suggests evidence for such an occurrence during ASCOS.

On 20 August (DoY 233), during the 08:00 helicopter flight, a broad atmospheric layer with raised concentrations of $D_{>300}$ particles was detected between ca. $800 \mathrm{~m}$ and 2000 ma.g.l., with concentrations over $10 \mathrm{~cm}^{-3}$ (Fig. 12). Local sources, found at the air-sea interface, are not present at these altitudes. Furthermore, the high atmospheric stability prevents mixing between the surface and the free 
troposphere. Consequently, the only explanation for such a spike in concentration is long-range transport. The more pertinent question therefore regards the source of the polluted air parcels advected over the high Arctic pack ice.

Wildfires in Siberia are one such possible source. Combustion of organic material during wildfires generates heat and moisture. This in turn leads to buoyancy-forced vertical and horizontal circulations of air and advection of hot gases and by-products of combustion (Jenkins et al., 2001). This process creates a very efficient mechanism for the rapid uplift of air containing large amounts of smoke particles, which, importantly, are good condensation nuclei (Reid et al., 2005). Furthermore, biomass burning is one of the largest sources of accumulation-mode particles (Reid et al., 2005). Finally, the weak sinks experienced by accumulation-mode particles result in long residence times - on the order of a few tens of days - in the lower and middle troposphere (Wallace and Hobbs, 2006). This ensures they can be transported long distances before being deposited.

In order to test the hypothesis of biomass burning as a source for free tropospheric plumes, five-day backward air trajectories (Fig. 13) were calculated for the case study flight and compared with the MODIS global fire map (Fig. 14) for the period in question.

The air mass trajectory shows that the origin of the air parcel is northern Siberia (Fig. 13), a region where numerous fires were detected by MODIS during the period under examination (Fig. 14). This supports the biomass burning hypothesis as a possible plume source. However, such evidence is not conclusive. Chemical tracer analysis, specifically an analysis of the vertical profiles of the mixing ratios of organic compounds such as acetonitrile and acetone, which are both produced in biomass burning plumes (Holzinger et al., 2005), would be instrumental in providing a definitive answer to the above hypothesis. Unfortunately, such measurements were not available for the flight in question. It should also be noted that other sources, such as emissions from gas flaring by the oil industry, have recently been suggested to be an important contribution to pollution plumes in the Arctic (Stohl et al., 2013).

This case study is typical of a number of profiles showing drastic increases in $D_{>300}$ particles within the free troposphere. The ensuing question is whether these particles can act as cloud condensation nuclei and contribute to the formation of low-level stratiform clouds over the pack ice in summer. In order to address this issue, it is necessary to consider the vertical structure of the troposphere over the high Arctic in summer. As mentioned above, the high Arctic PBL is typically a well-mixed shallow layer at the surface, capped by a temperature inversion. The inversion may at times be strong, such as when there is substantial advection of warmer air from lower latitudes while the free troposphere is stably stratified. In contrast to the processes in more southerly latitudes, deep convection, which could enhance mixing across the whole troposphere, does not occur other than possibly
NOAA HYSPLIT MODEL

Backward trajectories ending at 0800 UTC 20 Aug 08 GDAS Meteorological Data

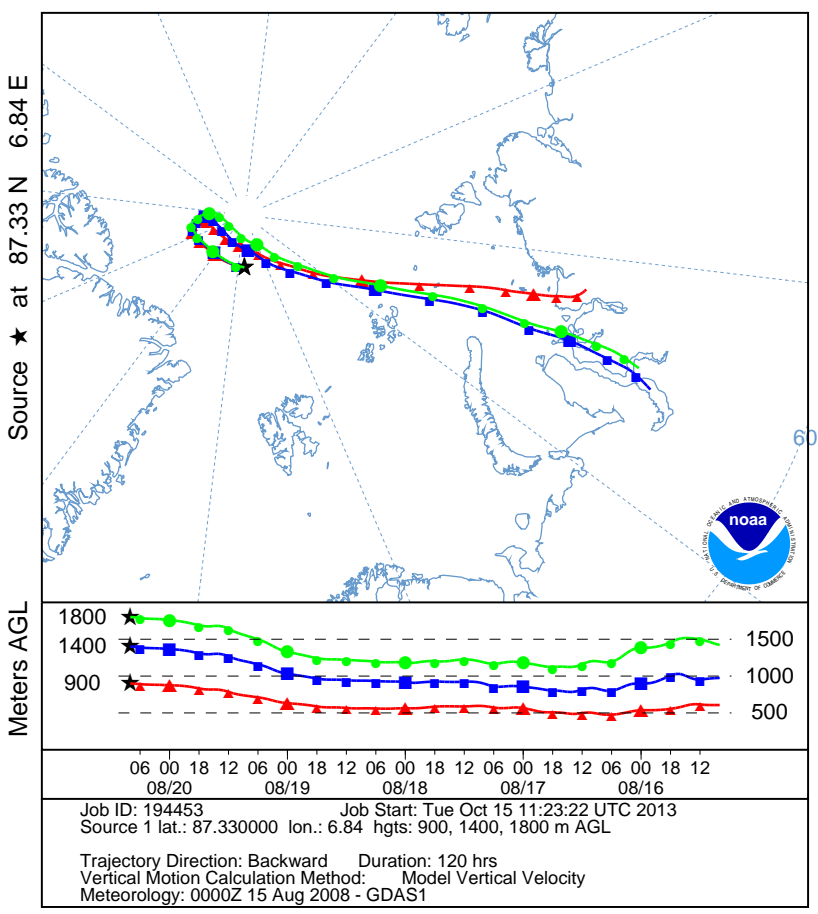

Fig. 13. Five-day backward air mass trajectory ending at 08:00 UTC, 20 August 2008 at $87.33^{\circ} \mathrm{N} 6.84^{\circ} \mathrm{E}$, calculated for $900 \mathrm{~m}$ (red), $1400 \mathrm{~m}$ (blue) and $1800 \mathrm{~m}$ (green) receptor-point altitude. Source: calculated using the HYSPLIT model http://www. arl.noaa.gov/HYSPLIT.php.

in frontal zones associated with passing weather systems. These characteristics limit mixing of particles from elevated plumes in the free troposphere into the PBL and the cloud layer. This requires that plumes are brought down to the top of the PBL where entrainment can occur, and the only mechanism that can bring elevated plumes down to the inversion is large-scale subsidence, which is a very slow process. As a result, long-range transport of plumes from farther south, where they are often lofted to several kilometres by convection or buoyant forest-fire sources, is unlikely to be a major factor contributing to $\mathrm{CCN}$ number concentrations within the lower atmosphere, and thus will not be a main contributor to the formation of low-level clouds. However, such transport events can be critical to upper-level cloud formation. In turn, these upper level clouds can impact the formation and maintenance of low-level Arctic stratocumulus by, for example, altered radiative heating/cooling rates. Thus, advection of particles aloft may indirectly impact the dynamic and thermodynamic processes that govern low-level stratocumulus. 


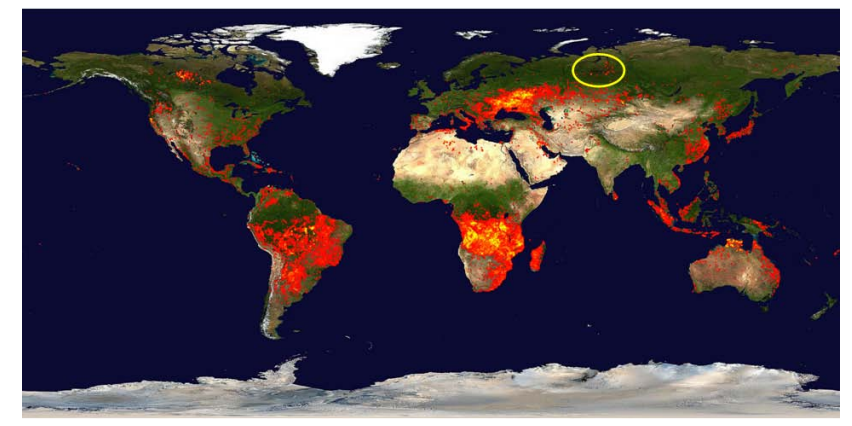

Fig. 14. Global fire map of all fires detected during a ten-day period (8-17 August 2008) by the Moderate Resolution Imaging Spectroradiometer (MODIS). Low fire counts are represented by red dots and high fire counts by yellow dots. Yellow oval shows the likely origin of the pollution plume observed during the ASCOS 2008 expedition helicopter flight on 20 August 2008. Source: http://lance-modis.eosdis.nasa.gov/cgi-bin/imagery/ firemaps.cgi (adapted by the author).

\section{Summary and conclusions}

This paper presents a study of aerosol particle vertical distributions over the summer Arctic pack ice based on unique data of atmospheric profiling. The analysis of aerosol concentration profiles in combination with meteorological data demonstrates that the vertical distribution of airborne particles over the summer Arctic pack ice is governed by the complicated interplay between local sources, long-distance transport and air mass origin, mixing events and cloud processing (a graphical representation of the processes is presented in Fig. 15). Furthermore, due to different sources, sinks and turnover times in the various well-defined atmospheric layers, there are distinct differences in aerosol particle characteristics within these layers.

The short residence time of ultrafine particles implies that the observed episodic sharp increases in near-surface concentrations of $D_{3-14}$ particles are of local origin. Such a source is constituted by bubble bursting in open leads in the pack ice (Leck et al., 2002; Bigg et al., 2004; Bigg and Leck, 2008; Leck and Bigg, 2010). Via a process involving dissipation of fog/cloud droplets and release and break-up of particles contained within the cloud droplets (Leck and Bigg, 1999, 2010), the open lead source is suggested to be responsible for the episodic occurrences, such as that during period 3 , on 29 August and at ground level during period 4, in the evening on 1 September. However, nucleation and early growth by condensable vapours, such as $\mathrm{H}_{2} \mathrm{SO}_{4}$ and organics, are also likely to contribute to the observed NPF event, with a combination of marine gel emissions and nucleation best explaining the observations according to a modeling study (Karl et al., 2013).

Meanwhile, transport of precursor gases and marine biogenic particles from the MIZ has been found to result in raised concentrations of $D_{>300}$ (data from helicopter pro-

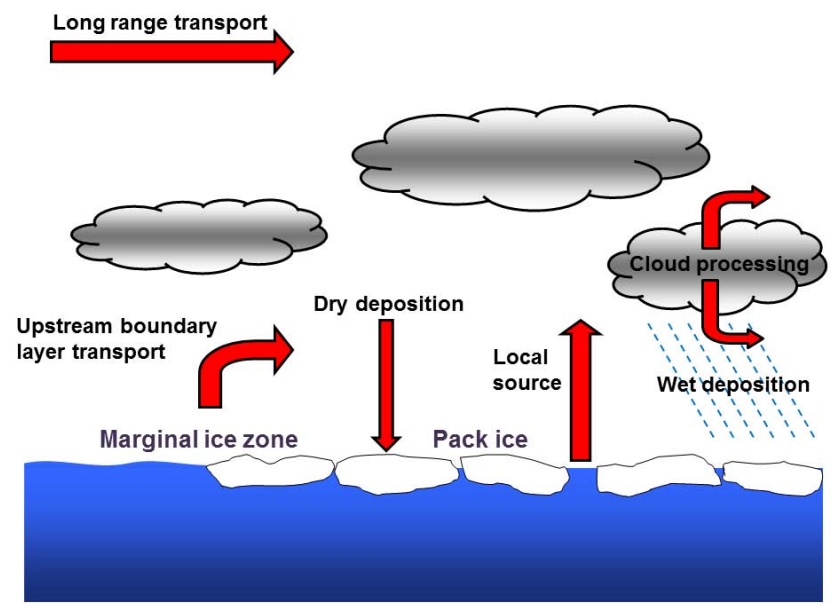

Fig. 15. Graphical representation of the sources and transport mechanisms of aerosol particles over the summer Arctic pack ice.

files) and accumulation-mode (data from TDMPS) particles within the PBL. This could involve both direct emissions of the larger accumulation-mode primary particles, as well as growth of particles via two processes, namely heterogeneous condensation and aerosol cloud processing. The former occurs when DMS oxidation products advected from open waters condense on sub-CCN-sized particles, whilst the latter involves $\mathrm{CCN}$-sized particles in cloud droplets and their growth via aqueous phase oxidation of dissolved gases. When cloud droplets evaporate, they leave behind raised concentrations of accumulation-mode particles, grown via the two processes described. In the process, the bimodal particle size distribution characteristic of cloud processed air masses is created (Hoppel et al., 1994), as observed within the PBL during period 1 and period 3 .

The $D_{>300}$ plumes observed within the free troposphere are believed to be caused by long-range pollution transport, with long atmospheric residence times of accumulationmode particles ensuring such particles can cover considerable distances before being deposited. Aircraft measurements carried out during the FIRE Arctic Clouds Experiment by Curry et al. (2000) have also shown long-range transport to contribute to pollution plumes aloft, while the nearsurface remained pristine. A likely source of such plumes is biomass burning in Siberia, creating both large amounts of accumulation-mode smoke particles and an efficient heatpowered mechanism for the uplift of the particles into the free troposphere, as discussed in the case study (Sect. 5).

Clouds were also found to be responsible for decreases in $D_{>300}$ particles, due to the high capability of these larger accumulation-mode particles to act as $\mathrm{CCN}$, and their uptake via cloud droplets, resulting in wet deposition of accumulation-mode particles, as suggested by Bigg et al. (2001). Such a mechanism is likely to have been responsible for diminishing the vertical extent of the raised $D_{>300}$ 
particle concentrations during period 3. Conversely, the extremely low concentration of $D_{>300}$ particles during period 4 led to the disappearance of clouds, resulting in a $\mathrm{CCN}$ limited regime, as described by Mauritsen et al. (2011), highlighting the importance of such particles for cloud formation.

Finally, the degree of cloud- and surface-generated turbulence, the coupling of layers between them, and, in particular, the height of the inversion base as a constraint to atmospheric mixing clearly had a large impact on the extent of aerosol plumes and their confinement to well-defined atmospheric layers. The characteristics of the summer Arctic atmosphere, namely the shallow boundary layer typically capped by a temperature inversion and the absence of deep convection, result in slow, large-scale subsidence being the only mechanism for bringing down free tropospheric plumes to the inversion layer, where entrainment into the PBL would be possible. Consequently, long-range transport plumes are unlikely to be mixed down to the PBL. This is an important point to be made in view of the origin of the particles acting as $\mathrm{CCN}$ over the Arctic pack ice; while free troposphere pollution plumes were frequently observed, we do not consider them to have any direct significant contribution to the $\mathrm{CCN}$ population active in low-level clouds. This is in agreement with the conclusions drawn by Bigg et al. (2001), who have shown, based on High Arctic helicopter measurements of DMS concentrations, that interchanges between the nearsurface and the free troposphere are infrequent, and longrange transport plumes can only marginally influence cloud formation in the stable layer below. However, long-range pollution plumes can influence higher clouds, as well as diabatic processes associated with precipitation, and thus influence the radiative balance of the PBL. In general, natural local sources, in combination with upstream boundary layer transport of precursor gases from the MIZ, must constitute the origin of $\mathrm{CCN}$ particles and thus be of importance for the formation of interior Arctic low-level clouds during summer, and subsequently, through cloud influences, on the melting and freezing of sea ice.

The profiles of aerosol particle concentrations described in this paper constitute the most extensive measurements of vertical aerosol distributions over the high Arctic to date. Nonetheless, many open questions remain, necessitating further aerosol measurements. Most important in this context is the development of platforms capable of providing comprehensive aerosol measurements while operating in the supercooled clouds and icing conditions of the high Arctic. This could be accomplished e.g. via adaptation of unmanned aerial vehicles to Arctic conditions, and would provide valuable in-cloud aerosol measurements, as opposed to the predominantly out-of-cloud helicopter measurements presented in this paper. Secondly, deployment of more extensive and improved remote sensing instrumentation would be of great benefit for measurements of turbulence and cloud properties, providing crucial data for the assessment of the relation- ships between aerosol particle concentration profiles, turbulent mixing and cloud properties.

Acknowledgements. We gratefully acknowledge L. Orr and O. Öhlund for the help in the quality assurance of the helicopter aerosol and meteorological data, and Thorsten Mauritsen for help with preparation of the meteorological instrumentation. This work is part of ASCOS (the Arctic Summer Cloud Ocean Study, www.ascos.se). ASCOS was made possible by funding from the Knut and Alice Wallenberg Foundation and the DAMOCLES European Union 6th Framework Program Integrated Research Project. The Swedish Polar Research Secretariat (SPRS) provided access to the icebreaker Oden and logistical support. We are grateful to the ASCOS science crew for supplying high-quality-controlled observations to us, especially I. Brooks, C. Birch, T. Mauritsen, M. Shupe and O. Persson. We are also grateful to the SPRS logistical staff and to Oden's Captain Mattias Peterson and his crew. ASCOS is an IPY project under the Air-Ice Chemical Interactions (AICI)-International Polar Year (IPY) umbrella and an endorsed Surface-Ocean Lower Atmosphere Study (SOLAS) project. Support for this work was provided by the Swedish Research Council (VR) and the Knut and Alice Wallenberg Foundation. We also gratefully acknowledge the support from the Nordic Council of Ministers through their Arctic Cooperation Programme as well as the Nordic Top-level Research Initiative CRAICC (Cryosphere-atmosphere interactions in a changing Arctic climate).

Edited by: G. de Leeuw

\section{References}

ACIA: Arctic Climate Impact Assesment, Cambridge University Press, 129 pp., 2005.

Barry, R. G., Serreze, M. C., and Maslanik, J. A.: The Arctic sea-ice climate system: observations and modeling, Rev. Geophys., 31, 397-422, 1993.

Bates, T. S., Quinn, P. K., Johnson, J. E., Corless, A., Brechtel, F. J., Stalin, S. E., Meinig, C., and Burkhart, J. F.: Measurements of atmospheric aerosol vertical distributions above Svalbard, Norway, using unmanned aerial systems (UAS), Atmos. Meas. Tech., 6, 2115-2120, doi:10.5194/amt-6-2115-2013, 2013.

Bigg, E. K. and Leck, C.: Cloud-active particles over the central Arctic Ocean, J. Geophys. Res., 106, 32155-32166, 2001a.

Bigg, E. K. and Leck, C.: Properties of the aerosol over the central Arctic Ocean, J. Geophys. Res., 106, 32101-32109, 2001 b.

Bigg, E. K. and Leck, C.: The composition of fragments of bubbles bursting at the ocean surface, J. Geophys. Res., 113, D11209, doi:10.1029/2007JD009078, 2008.

Bigg, E. K., Leck, C., and Nilsson, E. D.: Sudden changes in arctic atmospheric aerosol concentrations during summer and autumn, Tellus B, 48, 254-271, 1996.

Bigg, E. K., Leck, C., and Nilsson, E. D.: Sudden changes in aerosol and gas concentrations in the central Arctic marine boundary layer: causes and consequences, J. Geophys. Res., 106, 3216732185, 2001

Bigg, E. K., Leck, C., and Tranvik, L.: Particulates of the surface microlayer of open water in the central Arctic Ocean in summer, Mar. Chem., 91, 131-141, 2004. 
Chang, R. Y.-W., Leck, C., Graus, M., Müller, M., Paatero, J., Burkhart, J. F., Stohl, A., Orr, L. H., Hayden, K., Li, S.M., Hansel, A., Tjernström, M., Leaitch, W. R., and Abbatt, J. P. D.: Aerosol composition and sources in the central Arctic Ocean during ASCOS, Atmos. Chem. Phys., 11, 1061910636, doi:10.5194/acp-11-10619-2011, 2011.

Chin, W. C., Orellana, M. V., and Verdugo, P.: Spontaneous assembly of marine dissolved organic matter into polymer gels, Nature, 391, 568-572, 1998.

Covert, D. S., Wiedensohler, A., Aalto, P. P., Heintzenberg, J., McMurry, P. H., and Leck, C.: Aerosol number size distributions from 3 to $500 \mathrm{~nm}$ diameter in the arctic marine boundary layer during summer and autumn, Tellus B, 48, 197-212, 1996.

Curry, J. A. and Ebert, E. E.: Annual cycle of radiation fluxes over the Arctic Ocean: sensitivity to cloud optical properties, J. Climate, 5, 1267-1280, 1992.

Curry, J. A., Schramm, J. L., and Ebert, E. E.: Impact of clouds on the surface radiation balance of the Arctic Ocean, Meteorol. Atmos. Phys., 51, 197-217, 1993.

Curry, J. A., Hobbs, P. V., King, M. D., Randall, D. A., and Minnis, P.: FIRE arctic clouds experiment, B. Am. Meteorol. Soc., 81, 5-29, 2000.

Decho, A. W.: Microbial exopolymer secretions in ocean environments: their role(s) in food webs and marine processes, Oceanogr. Mar. Biol., 28, 73-153, 1990.

Draxler, R. R. and Rolph, G. D.: HYSPLIT (HYbrid Single-Particle Lagrangian Integrated Trajectory) Model, access via NOAA ARL READY Website, available at: http://ready.arl.noaa.gov/ HYSPLIT.php, NOAA Air Resources Laboratory, Silver Spring, MD, 2011.

Engvall, A.-C., Krejci, R., Ström, J., Minikin, A., Treffeisen, R., Stohl, A. and Herber, A.: In-situ airborne observations of the microphysical properties of the Arctic tropospheric aerosol during late spring and summer, Tellus B, 60, 392-404, doi:10.1111/j.1600-0889.2008.00348.x, 2008

Fu, P., Kawamura, K., Chen, J., and Barrie, L. A.: Isoprene, monoterpene, and sesquiterpene oxidation products in the high Arctic aerosols during late winter to early summer, Environ. Sci. Technol., 43, 4022-4028, 2009.

Garrett, T. J. and Zhao, C.: Increased Arctic cloud longwave emissivity associated with pollution from mid-latitudes, Nature, 440, 787-789, 2006

Garrett, T. J., Hobbs, P. V., and Radke, L. F.: High Aitken nucleus concentrations above cloud tops in the Arctic, J. Atmos. Sci., 59, 779-783, 2002

Graus, M., Müller, M., and Hansel, A.: High resolution PTR-TOF: quantification and formula confirmation of VOC in real time, J. Am. Soc. Mass Spectr., 21, 1037-1044, 2010.

Hamm, S. and Warneck, P.: The interhemispheric distribution and the budget of acetonitrile in the troposphere, J. Geophys. Res., 95, 20593-20606, 1990

Hegg, D. A., Ferek, R. J., and Hobbs, P. V.: Cloud condensation nuclei over the Arctic ocean in early spring, J. Appl. Meteorol., 34, 2076-2082, 1995.

Heintzenberg, J. and Leck, C.: Seasonal variations of the atmospheric aerosol near the top of the marine boundary layer over Spitsbergen related to the Arctic sulfur cycle, Tellus B, 46, 5267, 1994.
Heintzenberg, J. and Leck, C.: The summer aerosol in the central Arctic 1991-2008: did it change or not?, Atmos. Chem. Phys., 12, 3969-3983, doi:10.5194/acp-12-3969-2012, 2012.

Heintzenberg, J., Birmili, W., Wiedensohler, A., Nowak, A., and Tuch, T.: Structure, variability and persistence of the submicrometre marine aerosol, Tellus B, 56, 357-367, 2004.

Heintzenberg, J., Leck, C., Birmili, W., Wehner, B., Tjernström, M., and Wiedensohler, A.: Aerosol number-size distributions during clear and fog periods in the summer high Arctic: 1991, 1996 and 2001, Tellus B, 58, 41-50, 2006.

Hermann, M. and Wiedensohler, A.: Counting efficiency of condensation particle counters at low-pressures with illustrative data from the upper troposphere, J. Aerosol Sci., 32, 975-991, 2001.

Hill, M. K., Brooks, B, J., Norris, S. J., Smith, M. H., Brooks, I. M., and De Leeuw, G.: A Compact Lightweight Aerosol Spectrometer Probe (CLASP), J. Atmos. Ocean. Tech., 25, 1996-2006, 2008.

Holland, M. M. and Bitz, C. M.: Polar amplification of climate change in coupled models, Clim. Dynam., 21, 221-232, 2003.

Holland, M. M., Bitz, C. M., and Tremblay, B.: Future abrupt reductions in the summer Arctic sea ice, Geophy. Res. Lett., 33, L23503, doi:10.1029/2006GL028024, 2006.

Holzinger, R., Williams, J., Salisbury, G., Klüpfel, T., de Reus, M., Traub, M., Crutzen, P. J., and Lelieveld, J.: Oxygenated compounds in aged biomass burning plumes over the Eastern Mediterranean: evidence for strong secondary production of methanol and acetone, Atmos. Chem. Phys., 5, 39-46, doi:10.5194/acp-5-39-2005, 2005.

Hoppel, W. A., Frick, G. M., Fitzgerald, J. W., and Larson, R. E.: Marine boundary layer measurements on new particle formation and the effects non-precipitating clouds have on aerosol size distribution, J. Geophys. Res., 99, 14443-14459, 1994.

Intrieri, J. M., Fairall, C. W., Shupe, M. D., Persson, P. O. G., Andreas, E. L., Guest, P. S., and Moritz, R. E.: An annual cycle of Arctic surface cloud forcing at SHEBA, J. Geophys. Res., 107, 8039, doi:10.1029/2000JC000439, 2002.

IPCC, Intergovernmental Panel on Climate Change: Climate Change 2007: The Physical Science Basis. Contribution of Working Group I to the Fourth Assessment, Report of the Intergovernmental Panel on Climate Change, edited by: Solomon, S., Qin, D., Manning, M., Chen, Z., Marquis, M., Averyt, K. B., Tignor, M., and Miller, H. L., Cambridge University Press, Cambridge, UK and New York, NY, USA, 996 pp., 2007.

Jeffries, M. O. and Richter-Menge, J. (Eds.): Arctic, in: "State of the Climate in 2011", B. Am. Meteorol. Soc., 93, S127-S147, 2012.

Jenkins, M. A., Clark, T., and Coen, J.: Coupling atmospheric and firemodels, in: Forest Fire: Behavior and Ecological Effects, edited by: Johnson, E. A. and Miyanishi, K., Academic Press, San Diego, 257-302, 2001.

Jordan, A., Haidacher, S., Hanel, G., Hartungen, E., Märk, L., Seehauser, H., Schottkowsky, R., Sulzer, P., and Märk, T. D.: A high resolution and high sensitivity proton-transfer-reaction time-offlight mass spectrometer (PTR-TOF-MS), Int. J. Mass Spectrom., 286, 122-128, 2009.

Karl, M., Gross, A., Leck, C., and Pirjola, L.: A new flexible multicomponent model for the study of aerosol dynamics in the marine boundary layer, Tellus B, 63, 1001-1025, 2011. 
Karl, M., Leck, C., Gross, A., and Pirjola, L.: A study of new particle formation in the marine boundary layer over the central Arctic Ocean using a flexible multicomponent aerosol dynamic model, Tellus B, 64, 17158, doi:10.3402/tellusb.v64i0.17158, 2012.

Karl, M., Leck, C., Coz, E. and Heintzenberg, J.: Marine nanogels as a source of atmospheric nanoparticles in the high Arctic, Geophys. Res. Lett., 40, 3738-3743, doi:10.1002/grl.50661, 2013.

Kay, J. E. and Gettelman, A.: Cloud influence on and response to seasonal Arctic sea ice loss, J. Geophys. Res., 114, D18204, doi:10.1029/2009JD011773, 2009.

Kerminen, V. T. and Leck, C.: Sulfur chemistry over the central Arctic Ocean during the summer: gas-to-particle transformation, J. Geophys. Res., 106, 32087-32099, 2001.

Koch, D. and Hansen, J.: Distant origins of arctic black carbon: a Goddard Institute for Space Studies modelE experiment, J. Geophys. Res., 110, D18104, doi:10.1029/2004JD005296, 2005.

Leck, C. and Bigg, E. K.: Aerosol production over remote marine areas - a new route, Geophy. Res. Lett., 26, 3577-3580, 1999.

Leck, C. and Bigg, E. K.: Biogenic particles in the surface microlayer and overlaying atmosphere in the central Arctic Ocean during summer, Tellus B, 57, 305-316, 2005a.

Leck, C. and Bigg, E. K.: Source and evolution of the marine aerosol - a new perspective, Geophys. Res. Lett., 32, L19803, doi:10.1029/2005GL023651, 2005b.

Leck, C. and Bigg, E. K.: A modified aerosol-cloud-climate feedback hypothesis, Environ. Chem., 4, 400-403, 2007.

Leck, C. and Bigg, E. K.: New particle formation of marine biological origin, Aerosol Sci. Tech., 44, 570-577, 2010.

Leck, C. and Persson, C.: The central Arctic Ocean as a source of dimethyl sulfide: seasonal variability in relation to biological activity, Tellus B, 48, 156-177, 1996a.

Leck, C. and Persson, C.: Seasonal and short-term variability in dimethyl sulfide, sulfur oxide and biogenic sulfur and sea salt aerosol particles in the Arctic marine boundary layer during summer and autumn, Tellus B, 48, 272-299, 1996 b.

Leck, C., Larsson, U., Bågander, L.-E., Johansson, S., and Hajdu, S.: DMS in the Baltic Sea - annual variability in relation to biological activity. J. Geophys. Res., 95, 3353-3363, 1990.

Leck, C., Bigg, E. K., Covert, D. S., Heintzenberg, J., Maenhaut, W., Nilsson, E. D., and Wiedensohler, A.: Overview of the atmospheric research program during the International Ocean Expedition of 1991 (IAOE-1991) and its scientific results, Tellus B, 48, 136-155, 1996.

Leck, C., Nilsson, E. D., Bigg, E. K., and Bäcklin, L.: The Atmospheric program on the Arctic Ocean Expedition in the summer of 1996 (AOE-96) - a technical overview - outline of experimental approach, instruments, scientific objectives, J. Geophys. Res., 106, 32051-32067, 2001.

Leck, C., Norman, M., Bigg, E. K., and Hillamo, R.: Chemical composition and sources of the high Arctic aerosol relevant for cloud formation, J. Geophys. Res., 107, 4135, doi:10.1029/2001JD001463, 2002.

Leck, C., Tjernström, M., Matrai, P., Swietlicki, E., and Bigg, E. K.: Can marine micro-organisms influence melting of the Arctic pack ice?, EOS T. Am. Geophys. Un., 85, 25-36, 2004.

Lindsay, R. W., Zhang, J., Schweiger, A., Steele, M., and Stern, H.: Arctic sea-ice retreat in 2007 follows thinning trend, J. Climate, 22, 165-176, 2009.
Lundén, J., Svensson, G., Wisthaler, A., Tjernström, M., Hansel, A., and Leck, C.: The vertical distribution of atmospheric DMS in the high Arctic summer, Tellus B, 62, 160-171, 2010.

Mauritsen, T., Sedlar, J., Tjernström, M., Leck, C., Martin, M., Shupe, M., Sjogren, S., Sierau, B., Persson, P. O. G., Brooks, I. M., and Swietlicki, E.: An Arctic CCN-limited cloud-aerosol regime, Atmos. Chem. Phys., 11, 165-173, doi:10.5194/acp-11-165-2011, 2011.

Maykut, G. A. and Unterstiener, N.: Some results from timedependant thermodynamic model of sea-ice, J. Geophys. Res., 76, 1550-1575, 1971.

Moran, K. P., Martner, B. E., Post, M. J., Kropfli, R. A., Welsh, D. C., and Widener, K. B.: An unattended cloud-profiling radar for use in climate Research, B. Am. Meteorol. Soc., 79, 443-455, 1998.

Müller, M., Graus, M., Ruuskanen, T. M., Schnitzhofer, R., Bamberger, I., Kaser, L., Titzmann, T., Hörtnagl, L., Wohlfahrt, G., Karl, T., and Hansel, A.: First eddy covariance flux measurements by PTR-TOF, Atmos. Meas. Tech., 3, 387-395, doi:10.5194/amt-3-387-2010, 2010.

Nilsson, E. D.: Planetary boundary layer structure and air mass transport during the International Arctic Ocean Expedition 1991, Tellus B, 48, 178-196, 1996.

Nilsson, E. D. and Leck, C.: A pseudo-Lagrangian study of the sulfur budget in the remote Arctic marine boundary layer, Tellus B, 54, 213-230, 2002.

Nilsson, D. E., Rannik, Ü, Swietlicki, E., Leck, C., Aalto, P. P., Zhou, J., and Norman, M.: Turbulent aerosol fluxes over the Arctic Ocean 2. Wind-driven sources from the sea, J. Geophys. Res., 106, 32139-32154, 2001.

Norris, S. J., Brooks, I. M., de Leeuw, G., Sirevaag, A., Leck, C., Brooks, B. J., Birch, C. E., and Tjernström, M.: Measurements of bubble size spectra within leads in the Arctic summer pack ice, Ocean Sci., 7, 129-139, doi:10.5194/os-7-129-2011, 2011.

Orellana, M. V., Petersen, T. W., Diercks, A. H., Donohue, S., Verdugo, P., and van den Engh, G.: Marine microgels: optical and proteomic fingerprints, Mar. Chem., 105, 229-239, 2007.

Orellana, M. V., Matrai, P. A., Leck, C., Rauschenberg, C. D., Lee, A. M., and Coz, E.: Marine microgels as a source of cloud condensation nuclei in the high Arctic, P. Natl. Acad. Sci. USA, 108, 13612-13617, 2011.

Paatero, J., Vaattovaara, P., Vestenius, M., Meinander, O., Makkonen, U., Kivi, R., Hyvärinen, A., Asmi, E., Tjernström, M., and Leck, C.: Finnish contribution to the Arctic Summer Cloud Ocean Study (ASCOS) expedition, Arctic Ocean 2008, Geophysica, 45, 119-146, 2009.

Paatero, J., Buyukay, M., Holmén, K., Hatakka, J., and Viisanen, Y.: Seasonal variation and source areas of airborne lead-210 at NyAllesund in the high Arctic, Polar Res., 29, 345-352, 2010.

Pacyna, J. M. and Oehme, M.: Long-range transport of some organic compounds to the Norwegian Arctic, Atmos. Environ., 22, 243-257, 1988.

Prenni, A. J., Harrington, J. Y., Tjernström, M., DeMott, P. J., Avramov, A., Long, C. N., Kreidenweis, S., M., Olsson, P. Q., and Verlinde, J.: Can ice-nucleating aerosols affect Arctic seasonal climate?, B. Am. Meteorol. Soc., 88, 541-550, 2007.

Quinn, P. K., Shaw, G., Andrews, E., Dutton, E. G., RuohoAirola, T., and Gong, S. L.: Arctic haze: current trends and knowledge gaps, Tellus B, 59, 99-114, 2007. 
Quinn, P. K., Bates, T. S., Schulz, K., and Shaw, G. E.: Decadal trends in aerosol chemical composition at Barrow, Alaska: 19762008, Atmos. Chem. Phys., 9, 8883-8888, doi:10.5194/acp-98883-2009, 2009.

Raisanen, J.: $\mathrm{CO}_{2}$-induced climate change in the Arctic area in the CMIP2 experiments, SWECLIM Newsletter, 11, 23-28, 2001.

Ramanathan, V., Cess, R. D., Harrison, E. F., Minnis, P., Barkstrom, B. R., Ahmed, E., and Hartmann, D.: Cloud-radiative forcing and climate: results from the Earth Radiation Budget Experiment, Science, 243, 57-63, 1989.

Reid, J. S., Koppmann, R., Eck, T. F., and Eleuterio, D. P.: A review of biomass burning emissions part II: intensive physical properties of biomass burning particles, Atmos. Chem. Phys., 5, 799825, doi:10.5194/acp-5-799-2005, 2005.

Rolph, G. D.: Real-time Environmental Applications and Display sYstem (READY), available at: http://ready.arl.noaa.gov, NOAA Air Resources Laboratory, Silver Spring, MD, 2011.

Schneider, S. H.: Cloudiness as a global climate feedback mechanism: the effects on the radiation balance and surface temperature of variations in cloudiness, J. Atmos. Sci., 29, 1413-1422, 1972.

Sedlar, J., Tjernström, M., Maurtisen, T., Shupe, M.D., Brooks, I.M., Persson, P. O. G., Birch, C. E., Leck, C., Sirevaag, A., and Nicolaus, M.: A transitioning Arctic surface energy budget: the impacts of solar zenith angle, surface albedo and cloud radiative forcing, Climatic Dynam., 37, 1643-1660, doi:10.1007/s00382010-0937-5, 2011.

Sedlar, J., Shupe, M. D., and Tjernström, M.: On the relationship between thermodynamic structure and cloud top, and its climate significance in the Arctic, J. Climate, 25, 2374-2393, 2012.

Serreze, M. C. and Francis, J. A.: The arctic amplification debate, Climatic Change, 76, 241-264, 2006.

Shipham, M. C., Bachmeier, A. S., Cahoon Jr., D. R., and Browell, E. V.: Meteorological overview of the Arctic Boundary Layer Expedition (ABLE 3A) flight series, J. Geophys. Res., 97, 16395-16419, 1992.

Shupe, M. D., Persson, P. O. G., Brooks, I. M., Tjernström, M., Sedlar, J., Mauritsen, T., Sjogren, S., and Leck, C.: Cloud and boundary layer interactions over the Arctic sea ice in late summer, Atmos. Chem. Phys., 13, 9379-9399, doi:10.5194/acp-139379-2013, 2013.

Soden, B. J. and I. M. Held: An assessment of climate feedbacks in coupled ocean-atmosphere models, J. Climate, 19, 3354-3360, 2006.

Stohl, A.: Characteristics of atmospheric transport into the Arctic troposphere, J. Geophys. Res., 111, D11306, doi:10.1029/2005JD006888, 2006.

Stohl, A., Andrews, E., Burkhart, J. F., Forster, C., Herber, A., Hoch, S. W., Kowal, D., Lunder, C., Mefford, T., Ogren, J. A., Sharma, S., Spichtinger, N., Stebel, K., Stone, R., Ström, J., Tørseth, K., Wehrli, C., and Yttri, K. E.: Pan-Arctic enhancements of light absorbing aerosol concentrations due to North American boreal forest fires during summer 2004, J. Geophys. Res., 111, D22214, doi:10.1029/2006JD007216, 2006.

Stohl, A., Klimont, Z., Eckhardt, S., and Kupiainen, K.: Why models struggle to capture Arctic Haze: the underestimated role of gas flaring and domestic combustion emissions, Atmos. Chem. Phys. Discuss., 13, 9567-9613, doi:10.5194/acpd13-9567-2013, 2013.
Tjernström, M.: The summer Arctic boudary layer during the Arctic Ocean Experiment 2001 (AOE-2001), Bound.-Lay. Meteorol., 117, 5-36, 2005.

Tjernström, M: Is there a diurnal cycle in the summer cloud-capped arctic boundary layer?, J. Atmos. Sci., 64, 3970-3986, 2007.

Tjernström, M., Leck, C., Persson, P. O. G., Jensen, M. L., Oncley, S. P., and Targino, A.: The summertime Arctic atmosphere: meteorological measurements during the Arctic Ocean Experiment 2001, B. Am. Meteorol. Soc., 85, 1305-1321, doi:10.1175/BAMS-85-9-1305, 2004.

Tjernström, M., Birch, C. E., Brooks, I. M., Shupe, M. D., Persson, P. O. G., Sedlar, J., Mauritsen, T., Leck, C., Paatero, J., Szczodrak, M., and Wheeler, C. R.: Meteorological conditions in the central Arctic summer during the Arctic Summer Cloud Ocean Study (ASCOS), Atmos. Chem. Phys., 12, 6863-6889, doi:10.5194/acp-12-6863-2012, 2012.

Tjernström, M., Leck, C., Birch, C. E., Brooks, B. J., Brooks, I. M., Bäcklin, L., Chang, R. Y.-W., Granath, E., Graus, M., Hansel, A., Heintzenberg, J., Held, A., Hind, A., de la Rosa, S., Johnston, P., Knulst, J., de Leeuw, G., Di Liberto, L., Martin, M., Matrai, P. A., Mauritsen, T., Müller, M., Norris, S. J., Orellana, M. V., Orsini, D. A., Paatero, J., Persson, P. O. G., Gao, Q., Rauschenberg, C., Ristovski, Z., Sedlar, J., Shupe, M. D., Sierau, B., Sirevaag, A., Sjogren, S., Stetzer, O., Swietlicki, E., Szczodrak, M., Vaattovaara, P., Wahlberg, N., Westberg, M., and Wheeler, C. R.: The Arctic Summer Cloud-Ocean Study (ASCOS): overview and experimental design, Atmos. Chem. Phys. Discuss., 13, 1354113652, doi:10.5194/acpd-13-13541-2013, 2013.

Wallace, J. M. and Hobbs, P. V.: Atmospheric Science: an Introductory Survey, 2nd ed., International Geophysics Series, 92, Academic Press, 176 pp., 2006.

Walsh, J. E. and Chapman, W. L.: Arctic cloud-radiation temperature associations in observational data and atmospheric reanalysis, J. Climate, 11, 3030-3045, 1998.

Warneke, C., Bahreini, R., Brioude, J., Brock, C. A., de Gouw, J. A., Fahey, D. W., Froyd, K. D., Holloway, J. S., Middlebrook, A., Miller, L., Montzka, S., Murphy, D. M., Peischl, J., Ryerson, T. B., Schwarz, J. P., Spackman, J. R., and Veres, P.: Biomass burning in Siberia and Kazakhstan as an important source for haze over the Alaskan Arctic in April 2008, Geophys. Res. Lett., 36, L02813, doi:10.1029/2008GL036194, 2009.

Warneke, C., Froyd, K. D., Brioude, J., Bahreini, R., Brock, C. A., Cozic, J., de Gouw, J. A., Fahey, D. W., Ferrare, R., Holloway, J. S., Middlebrook, A. M., Miller, L., Montzka, S., Schwarz, J. P., Sodemann, H., Spackman, J. R., and Stohl, A.: An important contribution to springtime Arctic aerosol from biomass burning in Russia, Geophys. Res. Lett., 37, L01801, doi:10.1029/2009GL041816, 2010.

Westwater, E., Han, Y., Irisov, V. G., Leuskiy, V., Kadygrov, E. N., and Viazankin, S. A.: Remote sensing of boundary layer temperature profiles by a scanning 5-mm microwave radiometer and RASS: comparison experiments, J. Atmos. Ocean. Tech., 16, 805-818, 1999.

Wiedensohler, A., Covert, D. A., Swietlicky, E. S., Aalto, P., and Heintzenberg, J., Occurrence of an ultrafine particle mode less than $20 \mathrm{~nm}$ in diameter in the marine boundary layer during the Arctic summer, Tellus B, 48, 213-222, 1996.

Yamanouchi, T., Treffeisen, R., Herber, A., Shiobara, M., Yamagata, S., Hara, K., Sato, K., Yabuki, M., Tomikawa, Y., Rinke, 
A., Neuber, R., Schumachter, R., Kriews, M., Ström, J., Schrems, O., and Gernandt, H.: Arctic Study of Tropospheric Aerosol and Radiation (ASTAR) 2000: Arctic haze case study, Tellus B, 57, 141-152, doi:10.1111/j.1600-0889.2005.00140.x, 2005.

Zhang, K. M. and Wexler, A. S.: A hypothesis for growth of fresh atmospheric nuclei, J. Geophys. Res., 107, 4577, doi:10.1029/2002JD002180, 2002.
Zhang, T., Stamnes, K., and Bowling, S. A.: Impact of clouds on surface radiative fluxes and snowmelt in the Arctic and Subarctic, J. Climate, 9, 2110-2123, 1996.

Ziemba, L. D., Dibb, J. E., Griffin, R. J., Huey, L. G., and Beckman, P. J.: Observations of particle growth at a remote, Arctic site, Atmos. Environ., 44, 1649-1657, 2010. 